\title{
On the robustness of seismic moment tensor inversions for mid-ocean earthquakes: the Azores archipelago
}

\author{
M. Frietsch, ${ }^{1}$ A.M.G Ferreira, ${ }^{1,2}$ D. Vales ${ }^{3}$ and F. Carrilho ${ }^{3}$ \\ ${ }_{1}^{1}$ Department of Earth Sciences, Faculty of Maths and Physical Sciences, University College London, WC1E 6BT, UK. E-mail: michael.frietsch.14@ucl.ac.uk \\ ${ }^{2}$ CERIS, Instituto Superior Técnico, Universidade de Lisboa, Av. Rovisco Pais 1, 1049-001 Lisboa, Portugal \\ ${ }^{3}$ Instituto Português do Mar e da Atmosfera, Rua C do Aeroporto, 1749-077 Lisboa, Portugal
}

Accepted 2018 July 20. Received 2018 July 3; in original form 2017 November 24

\begin{abstract}
S UMMAR Y
Source models of mid-oceanic earthquakes are often based only on far-field, teleseismic data. The uncertainties of all source parameters are rarely quantified, which restricts our understanding of how these events slip and how oceanic lithosphere is formed. Here, we perform moment tensor inversions for five $M_{\mathrm{w}}$ 4.6-5.9 earthquakes that occurred in the Azores archipelago near the Mid-Atlantic Ridge in 2013-2016, taking advantage of the recently expanded seismic network in the region. We assess moment tensor uncertainties due to data and Earth model variability as well as the robustness of teleseismic versus local data inversions. We find that for the events studied: (i) existing 1-D Earth models of the region based on receiver function data lead to a slightly improved data fit of local data compared to a widely used regional model based on active seismic surveys; and (ii) using different 1-D Earth models in the local data inversions leads to a variability in the retrieved source parameters of $15^{\circ}-30^{\circ}$ in fault strike, $5^{\circ}-20^{\circ}$ in dip, and $20^{\circ}-60^{\circ}$ in rake, depending on the earthquake's magnitude and location. We study in detail the $M_{\mathrm{w}} 5.92013$ April 30 Povoação basin earthquake using 1-D and 3-D waveform modelling, for which reported values of strike, dip, and rake in earthquake catalogues differ by $60^{\circ}, 35^{\circ}$, and $80^{\circ}$. We find that our moment tensor solutions show a lower variability than in the catalogues and exhibit a persistent non-double-couple component of $\sim 40-60$ per cent, which is not due to a volumetric change. We suggest that it is potentially due to geometrically complex faulting in the Povoação basin, notably curved faults. We find that the retrieved moment tensor solutions depend strongly on the earthquake's location. If an accurate location is used, joint inversions of local and teleseismic data can help to stabilize moment tensor solutions of oceanic earthquakes and reduce parameter trade-offs, compared to inversions of local data alone.
\end{abstract}

Key words: Europe; Waveform inversion; Earthquake source observations; Mid-ocean ridge processes.

\section{INTRODUCTION}

The study of earthquakes occurring near mid-ocean ridges and oceanic transform faults provides a unique opportunity to explore the processes involved in the creation of oceanic lithosphere. These events are either of tectonic origin or associated with magmatism, and can show significant complexity (e.g. Bergman \& Solomon 1988, 1990; Abercrombie \& Ekström 2001, 2003; Pro et al. 2007; Aderhold \& Abercrombie 2016). Wide, diffuse zones of seismicity are sometimes observed (Marques et al. 2013; Escartín et al. 2003), indicating that deformation can occur in broad shear zones rather than being just localized at plate boundaries as predicted by plate tectonics.
Detailed analyses of the source process of mid-oceanic events can be difficult because they usually occur far from seismic stations. Many studies of mid-oceanic earthquakes rely on seismic observations in the far field, at teleseismic distances, which provide useful but restricted information about the event (e.g. López-Comino et al. 2015). In addition, despite efforts to quantify errors, for example in source depth (Tilmann et al. 2010; Sumy et al. 2013; Hauksson et al. 2014; Aderhold \& Abercrombie 2015), the uncertainties and nonuniqueness of other source parameters (e.g. strike, dip, rake, seismic moment, non-double-couple component) are rarely quantified.

Efforts done to better understand these events include monitoring seismicity with marine geophysical surveys (e.g. Smith et al. 2003; Schlindwein et al. 2015) and using constraints from seafloor 
bathymetry (Pan et al. 2002). These approaches have been primarily applied to specific study regions and, in the case of marine surveys, they are restricted to limited time periods. Ongoing initiatives to enhance the continuous coverage of the oceans may help change this situation in the future (e.g. Simons et al. 2009; Kawakatsu et al. 2014). In the past decade, permanent and temporary seismic networks have expanded greatly, including in some ocean islands such as the Azores archipelago, near the Mid-Atlantic Ridge. These new local data provide a key opportunity not only to study the earthquakes in the region, but also to assess the robustness and uncertainties of source models based on teleseismic data alone.

Seismic moment tensors are now routinely calculated by various agencies and projects at global, regional, and local scales (e.g. Dziewoński et al. 1981; Dreger et al. 1998; Kubo et al. 2002; Ekström et al. 2012; Duputel et al. 2012b; Konstantinou 2015). These moment tensor catalogues provide key information to identify active faults and to help understand regional active tectonics, seismic hazard, and earthquake mechanics. There can be substantial differences between the source parameters reported by different agencies for a given earthquake, notably for moderate magnitude mid-oceanic earthquakes. Several studies have investigated various factors contributing to moment tensor uncertainties, such as, data noise, restrictions in the forward modelling approach, and the earth model used (e.g. Ferreira \& Woodhouse 2006; Hjörleifsdöttir \& Ekström 2010; Ferreira et al. 2011; Valentine \& Trampert 2012; Duputel et al. 2012a; Weston et al. 2011; Scognamiglio et al. 2016). In addition, probabilistic inversion approaches including error quantification are also progressing (e.g. Wéber 2006; Duputel et al. 2012a; Stähler \& Sigloch 2014, 2016; Mustać \& Tkalcić 2016). Yet, in practice, most moment tensor determinations still lack comprehensive uncertainty quantification, which limits our understanding of the discrepancies between reported source models.

In this study, we examine the robustness of moment tensor inversions of five $M_{\mathrm{w}}$ 4.6-5.9 earthquakes in the Azores archipelago that occurred in 2013-2016. We take advantage of the significant expansion of the seismic network in the region in the past decade, which provides a unique opportunity to study mid-ocean earthquakes using local, regional, and teleseismic data. In addition, we perform a novel combination of 1-D and 3-D waveform modelling of the events using an unprecedented variety of 1-D and 3-D Earth models. This enables us to assess moment tensor uncertainties due to data and Earth model errors, and address the following questions: (i) How compatible are the moment tensor solutions obtained from local versus teleseismic data? (ii) What are the advantages/disadvantages of using local versus teleseismic data in the inversions? (iii) Can we reduce the variability in moment tensor solutions reported in the literature? Since for most remote oceanic earthquakes there are no available local data nor local Earth models, addressing these questions can help us better understand past and future events, putting much needed ranges on what can be fit by the data.

\section{SEISMO-TECTONICS OF THE AZORES ARCHIPELAGO}

The Azores archipelago comprises nine volcanic islands located near the tectonic triple junction where the North American, Eurasia, and Nubia plates interact (Fig. 1a). A change in orientation of the Mid-Atlantic Ridge from NW-SE to an orientation nearly N-S and the existence of a mantle melting anomaly (Schilling 1975; Schilling et al. 1983) mark the Azores as a special segment of the Mid-Atlantic Ridge with high seismicity and active volcanism. The
Azores plateau, hosting the Azores islands is an area of thickened oceanic crust corresponding to a bathymetry anomaly with triangular shape (Searle 1976; Detrick et al. 1995; Luis et al. 1998; Gente et al. 2003; Dias et al. 2007; Georgen \& Sankar 2010; Silveira et al. 2010). The origin of the Azores plateau could be the result of ridgehotspot interaction as the $\mathrm{v}$-shaped ridges along the Mid-Atlantic Ridge suggest (Vogt 1979; Cannat et al. 1999; Escartín et al. 2001).

East of the Mid-Atlantic Ridge, two areas of deformation have been identified: (i) the incipient Princess Alice Rift (Fig. 1a), which links the Mid-Atlantic Ridge to the East Azores fracture zone; and, (ii) the Terceira rift, which goes from the Terceira island to near the island of Santa Maria, where it connects to the Gloria fault (Fernandes et al. 2006). The area linking the Mid-Atlantic Ridge to the Terceira rift is a diffuse triple junction area rather than a simple triple junction (Marques et al. 2013; Miranda et al. 2014). Importantly, the spreading rate gradually increases along the Mid-Atlantic Ridge from north $\left(19.5 \mathrm{~mm} \mathrm{yr}^{-1}\right.$ at $\left.40^{\circ} \mathrm{N}\right)$ to south $\left(22.5 \mathrm{~mm} \mathrm{yr}^{-1}\right.$ at $38^{\circ} \mathrm{N}$ ), making the opening of the Terceira Rift with a rate of about 2 to $2.7 \mathrm{~mm} \mathrm{yr}^{-1}$ possible (Marques et al. 2013). Recent geophysical surveys highlight complex fault systems, notably in the area of the Povoação Basin (Fig. 1a) where there are many active faults (e.g. Weiß et al. 2015).

Catalogues of historical seismicity in the Azores report large events with hazardous magnitudes of $M_{\mathrm{w}} 7$ and above (Fig. 1b). Gaspar et al. (2015) state that 31 destructive earthquakes have been registered in the Azores since the settlement of the archipelago (15th century) with no major events west of the Mid-Atlantic Ridge. Twenty-eight volcanic eruptions happened in the same time frame. Historically, the most destructive earthquake was the Vila Franca do Campo event in 1522 in the São Miguel island (Gaspar et al. 2015) with an intensity X (Silveira et al. 2003), leading to the destruction of the entire village and subsequently to 5000 deaths. Amongst the instrumentally recorded significant earthquakes are the $M_{\mathrm{w}} 6.8$ $1980 \mathrm{~W}$ of Terceira island, $M_{\mathrm{w}} 5.91997 \mathrm{SE}$ of Terceira island and $M_{\mathrm{W}} 6.01998$ Faial events (Borges et al. 2007). Major earthquakes in the archipelago often triggered landslides and even small tsunamis (Gaspar et al. 2015; Silva et al. 2015).

The former active East Azores fracture zone has no significant seismicity today, despite being clearly visible in bathymetric data (Fig. 1a). Recent high seismicity levels with moderate magnitude events are observed along the Terceira Rift and the Mid-Atlantic Ridge (Fig. 1a). The predominant faulting mechanisms of earthquakes in this region are normal or transform faulting with horizontal tensions on average in a $\mathrm{N} 25^{\circ} \mathrm{E}$ direction (Buforn et al. 1988; Custódio et al. 2016, Fig. 1b). The seismic moment tensor and hypocentre clustering analysis of Custódio et al. (2016) identified five clusters in the Azores: (i) two clusters along the Mid-Atlantic Ridge with normal faulting in NNE-SSW; (ii) two clusters along Terceira rift NW-SE; and, (iii) one cluster located in the Azores plateau between the Mid-Atlantic ridge and the Terceira rift with heterogeneous distribution of focal mechanisms. However, these studies were based on simple Earth models and did not include comprehensive uncertainty analyses. Here, we go beyond previous analyses by combining local, regional, and teleseismic data, along with 1-D and 3-D waveform modelling using a wide range of Earth models.

\section{METHODS}

We conduct two types of seismic moment tensor inversions: (i) local data inversions using 1-D Earth models; and (ii) teleseismic 

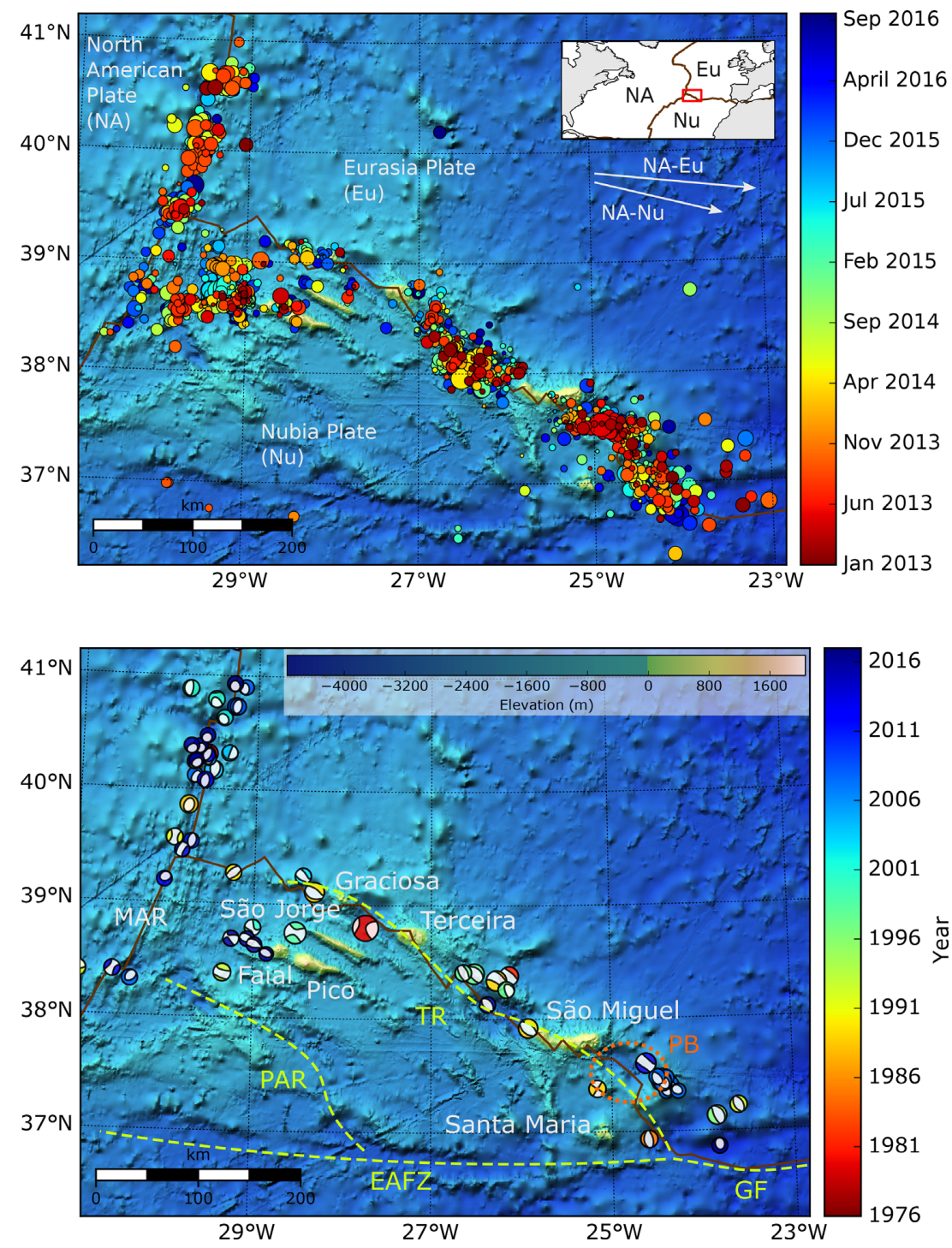

Figure 1. Top: seismicity in the Azores region since 2013 January 1, observed by the local seismic network of IPMA (IPMA 2016). The locations of the events are marked by circles, which are colour-coded by the days since 2013 January 1 and whose size is scaled by magnitude. The small inset illustrates the location of the Azores islands on a continental scale, at the tectonic triple junction of the North American (NA), Eurasian (Eu) and Nubian (Nu) plates. The two arrows in white show the relative plate velocities between NA-Eu and NA-Nu plates as predicted by NUVEL-1A (DeMets et al. 1994), taken from Mendes et al. (2013). Bottom: moment tensor solutions in the region since 1976, taken from the Global Centroid Moment Tensor (GCMT) catalogue (Dziewoński et al. 1981; Ekström et al. 2012). The focal mechanisms are plotted at the corresponding earthquake location and are colour-coded according to the year in which they occurred. The size of the focal mechanism is scaled by magnitude. The main tectonic faults shown are the East Azores Fault Zone (EAFZ), the Princess Alice Rift (PAR), the Terceira Rift (TR), the Mid-Atlantic Ridge (MAR) and the Gloria fault (GF) (dashed lines in light green). The Povoação Basin (PB) is highlighted with an orange dotted circle. The plate boundaries in brown are from Bird (2003). Topography and bathymetry are from SRTM30_PLUS (Becker et al. 2009).

and joint local-teleseismic data inversions using 3-D Earth models. The latter technique is only used for the largest event studied, the $M_{\mathrm{w}} 5.92013$ Aprile 30 earthquake.

\subsection{Moment tensor inversions of local data using 1-D Earth models}

We start by performing moment tensor inversions of local seismic data using the software package ISOLA written by Sokos \& Zahradník (2008, 2013). It consists of a Matlab graphical user interface and a set of Fortran codes to perform the computationally demanding parts such as the calculation of the Green's functions, the impulsive response of the medium. Full body and surface waveforms are fitted in the time domain to estimate the source parameters. After the data are pre-processed and a time window is set, the Green's functions are calculated for a layered 1-D medium with the discrete wavenumber method of Bouchon (1981) and Coutant (1989). A least-squares inversion is used to determine the deviatoric moment tensor solution minimizing a $L_{2}$-norm misfit function (Sokos \& Zahradník 2013). The $L_{2}$-norm misfit $m$ evaluates the agreement between the vector of the observed data $d$ and the synthetics $s\left(m=\frac{(s-d)^{T}(s-d)}{d^{T} d}\right)$. We perform inversions both allowing and not allowing a volumetric change in the earthquake source process. The latter condition is obtained by imposing the trace of the moment tensor to vanish in the inversions. Conversely, the spacetime centroid location, including the source depth, is retrieved with a grid search scheme. The correlation coefficient between the data 


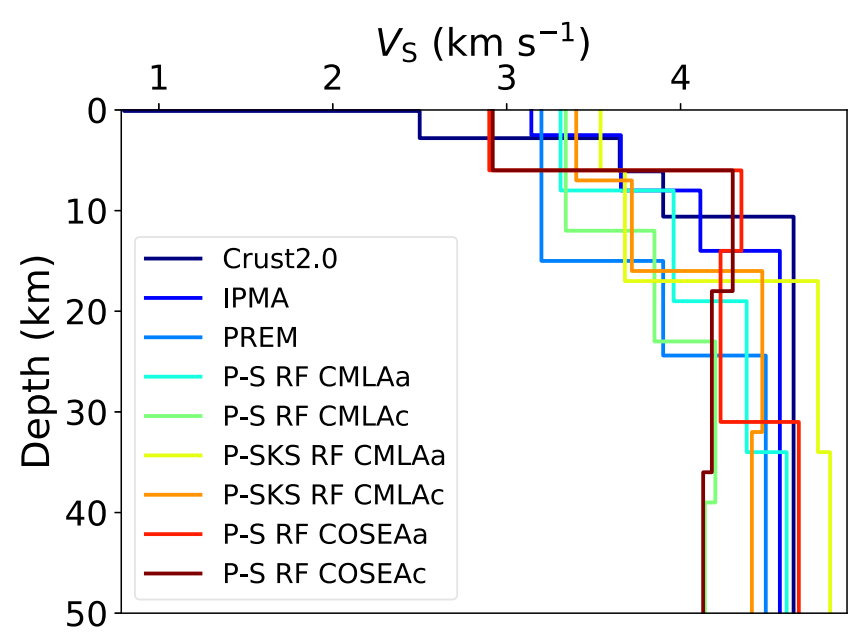

Figure 2. Comparison of local 1-D $V$ s models used in our moment tensor inversions: IPMA, PREM, CRUST2.0 and the different models derived from the receiver function of Silveira et al. (2010). Data from station CMLA in São Miguel island was used to build the models: (i) P-S CMLAa and P-S CMLAc, which are based on $P$ and $S$ receiver functions; and, (ii) P-SKS CMLAa and P-SKS CMLAc, which are based on $P$ and $S K S$ receiver functions. Models P-S COSEAa and P-S COSEAc were obtained from $P$ and $S$ receiver functions from stations from the temporary seismic network COSEA (Fig. 4). For the models marked with (c), Silveira et al. (2010) applied traveltime residuals of teleseismic $P$ and $S$ arrivals before the inversion process in an attempt to reduce the non-uniqueness of the joint inversion of $P$ and $S$ receiver functions.

and theoretical seismograms is used as a measure for the quality of the waveform fits for the different centroids tested.

\subsubsection{1-D Earth models}

Nine 1-D earth models are used to estimate their influence on the source parameters obtained from the inversion of local seismic recordings from the events in the Azores:

(i) The 1-D Earth model that the Portuguese seismic monitoring agency (IPMA) uses to locate seismicity in the Azores region is adapted from the model of Hirn et al. (1980). This model is based on an active seismic study in São Miguel island, which determined a crustal thickness of $14 \mathrm{~km}$ (Fig. 2).

(ii) The PREM model (Dziewoński \& Anderson 1981), which is used for reference.

(iii) A 1-D profile corresponding to the Azores region from the CRUST2.0 model, which is a $2 \times 2$ deg crustal model (Bassin et al. 2000). CRUST2.0 is a compilation of results from active seismic surveys and receiver function studies from data-rich regions which are extrapolated to data-poor regions. The model does not change laterally for the studied region in the Azores island. Given that CRUST2.0 only includes information about the crust, we superimpose PREM's mantle on CRUST2.0 for depths greater than $12 \mathrm{~km}$.

(iv) Six 1-D profiles obtained from a receiver function study of the Azores region by Silveira et al. (2010) (Fig. 2). This study used data from the permanent Global Seismographic Network (GSN) station CMLA in São Miguel island to obtain two models derived from the joint inversion of $P$ and $S$ receiver functions (model P-S CMLAa and P-S CMLAc in Fig. 2) and from $P$ and SKS receiver functions (model P-SKS CMLAa and P-SKS CMLAc in Fig. 2).
The remaining models P-S COSEAa and P-S COSEAc were obtained from $P$ and $S$ receiver functions from five temporary stations (FLO, COV, PSJO, PSCM, and PSMA). These stations were deployed between 2000 December and 2002 September as part of the Coordinated Seismic Experiment at Azores (COSEA, Fig. 4).

The corresponding profiles for the $P$-wave velocity $V_{p}$, quality factors $Q_{\kappa}, Q_{\mu}$, and the density $\rho$ can be found in Figs S1 and S2 in the Supporting Information.

\subsection{Moment tensor inversions of local and teleseismic data using 3-D Earth models}

We perform moment tensor inversions using both local and teleseismic data for the largest of the five earthquakes in our study, the $M_{\mathrm{w}}$ 5.9 Povoação basin event on 2013 April 30, which has the highest signal-to-noise ratio. We use a source inversion scheme that builds on the work of Weston et al. (2014); specifically, in this study, we added to the algorithm the capability to model local and regional waveforms using 3-D Earth models, and to allow the earthquake source to have a non-double-couple component. Considering a seismic moment tensor $f$ :

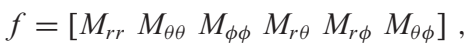

the theoretical seismograms $s$ can be written as:

$s=K f$,

where $K$ is a matrix with the six sensitivity kernels of the seismic waveforms with respect to each component of the moment tensor. The kernels are the partial derivatives of the synthetic waveforms with respect to the components of the moment tensor:

$K_{i}=\frac{\partial s}{\partial f_{i}}$.

The spectral element method (Komatitsch \& Tromp 1999) is used to compute the synthetics and the kernels for long-period teleseismic waveforms accurate down to a wave period of $T \sim 17 \mathrm{~s}$. In addition, we compute local and regional waveforms accurate down to a period of $T \sim 7 \mathrm{~s}$. The spectral element method is a highly accurate technique for seismic forward modelling in realistic 3-D Earth models. Despite being relatively expensive computationally, given the linear relationship between the moment tensor and the seismic waveforms (eq. 2), sensitivity kernels are pre-computed and stored before being used in the source inversions.

In our inversions, we use space-time locations of the event from two catalogues: (i) Global Centroid Moment Tensor (GCMT), and (ii) IPMA. In order to stabilize the inversions, the depth is fixed to $12 \mathrm{~km}$. It is well known that the source depth of shallow events is poorly constrained when using surface waveforms in CMT inversions (e.g. Dziewoński et al. 1981; Ferreira \& Woodhouse 2006). Thus, global catalogues often fix the source depth of shallow earthquakes (e.g. the GCMT catalogue often fixes it at $12 \mathrm{~km}$ depth). In turn, this can help better constrain the moment tensor, notably its dip-slip components (e.g. Dziewoński et al. 1981; Ekström et al. 2012). In the inversion scheme used to determine the moment tensor, a Monte Carlo approach is employed, whereby the $L_{2}$-norm misfit function $m$ defined in Section 3.1 is minimized by using the pre-calculated kernels and by exploring a wide range of source parameters. For a deviatoric moment tensor, the components are related to the seismic moment $M_{0}$, fault strike $\phi, \operatorname{dip} \delta$, and rake $\lambda$ and the compensated linear vector dipole component following the 
parametrization of Tape \& Tape (2015). A search over these parameters is carried out in the inversions. The Powell algorithm (Powell 1964) is used as a local search algorithm in the global optimization scheme.

\subsubsection{3-D Earth models}

We investigate the influence of 3-D Earth structure on our source inversions by using three different global 3-D whole mantle shear wave models combined with the CRUST2.0 (Bassin et al. 2000) crustal model:

(i) the isotropic S40RTS model (Ritsema et al. 2010);

(ii) the radially anisotropic model S362ANI (Kustowski et al. 2008), which includes perturbations in the 410 and $660 \mathrm{~km}$ mantle discontinuities; and,

(iii) the radially anisotropic SGLOBE-rani model (Chang et al. 2015).

Fig. 3 compares these three global mantle models, showing that their $V_{s}$ structures are similar in the uppermost mantle and in the lowermost mantle. At mid-mantle depths, there are larger differences between the models.

\subsubsection{Data weights}

We conduct source inversions combining local and teleseismic $P$ wave, $S$ wave, and surface waveforms. In order to jointly invert these different data types we weight them using the misfit function in our inversions (eq. 4 ), where $m_{k}$ is the $L_{2}$-norm misfit function defined in Section 3.1, for a given data type (i.e. local, teleseismic $P$ wave, $S$ wave or surface waveforms). $\alpha_{k}=\frac{1}{m_{\text {single }, k}}$ is the normalization factor, where $m_{\text {single, } k}$ is the minimum misfit obtained from a moment tensor inversion using only the single data type $k$. The total misfit is defined as:

$m_{\text {tot }}=\frac{1}{4} \sum_{k=1}^{N=4} \alpha_{k} \beta_{k} m_{k}$,

where $\beta_{k}$ is the weighting factor of data type $k$. Following Weston et al. (2014), we determine the optimal weighting factors $\beta_{k}$ by carrying out multiple joint inversions with a wide range of weights. After each joint data inversion, the corresponding misfit for each data set is compared to that from the individual data inversion. This comparison guides the adjustment in weights in the various inversions until we achieve a situation where the misfit deterioration in the joint inversions compared to the individual data inversions is of similar magnitude for all data sets. We found that for the 2013 $M_{\mathrm{w}} 5.9$ Povoação basin event studied, the best weighting factors are $\beta_{\text {local }}=8$ for the local data and $\beta_{k}=1$ for all the teleseismic data sets ( $P, S$, and surface waves).

\section{SEISMIC DATA}

\subsection{Earthquakes studied}

In order to ensure a reasonable local seismic data coverage, we focus on events with $M_{\mathrm{w}} \geq 4.6$ that occurred near to the central and easternmost islands of the Azores archipelago between 2013 and mid-2016. The five events studied have $M_{\mathrm{w}} 4.6-5.9$ and a fixed depth of $10 \mathrm{~km}$, as reported in the United States Geological Survey seismic catalogue. We use waveforms from the 2013 April 30
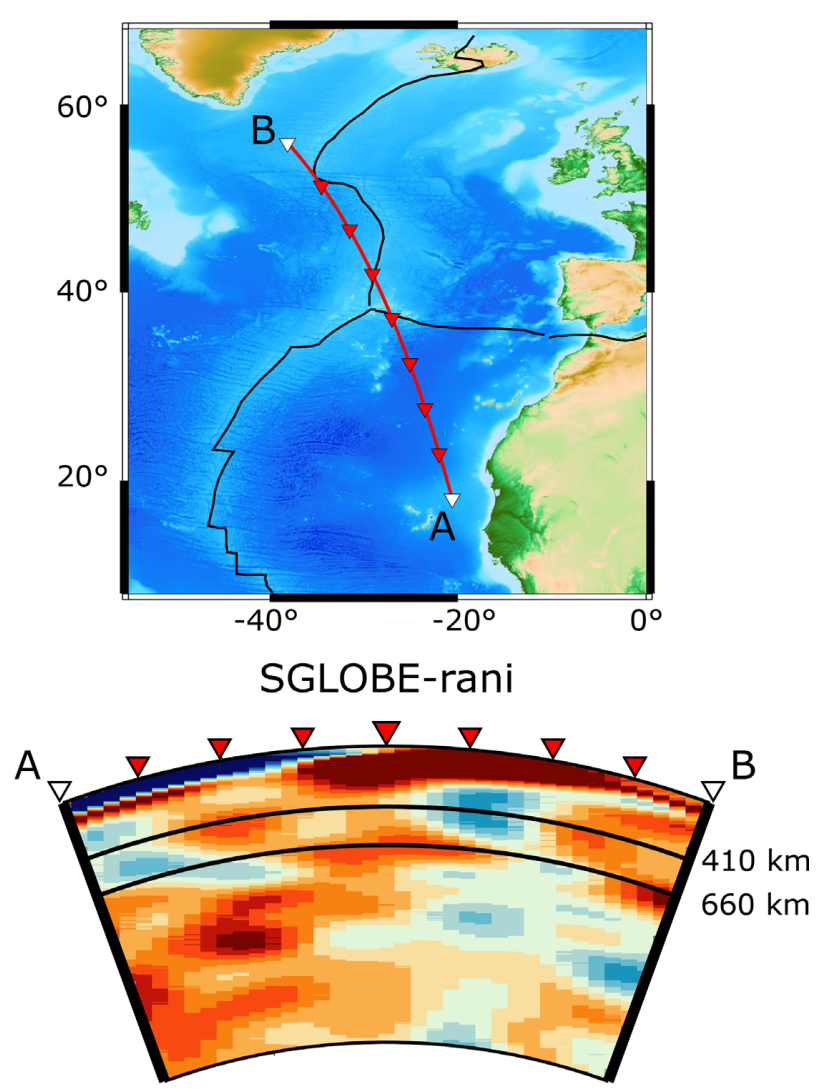

S40RTS

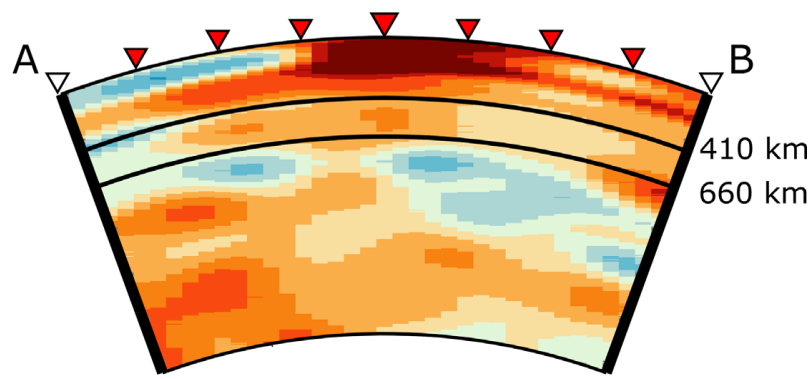

S362WMANI

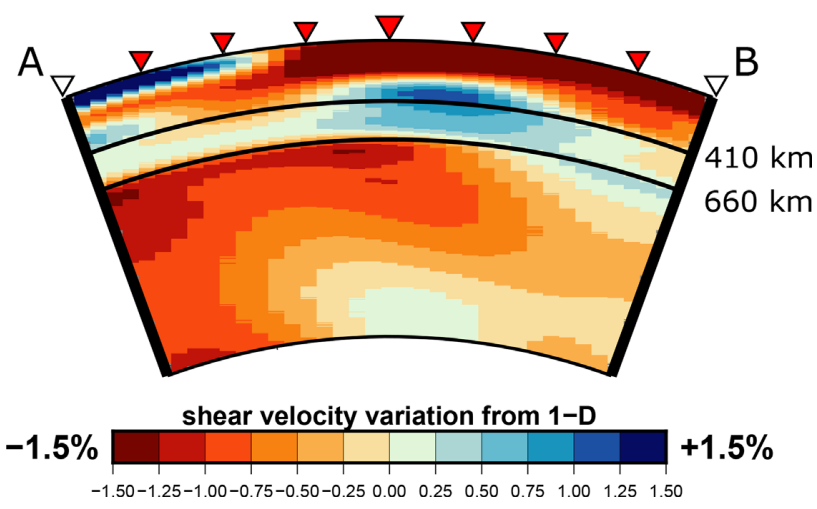

Figure 3. Comparison of cross-sections centred in the Azores region of the isotropic shear wave speed perturbations in mantle models S40RTS (Ritsema et al. 2010), S362ANI (Kustowski et al. 2008) and SGLOBE-rani (Chang et al. 2015). The velocity perturbations are plotted with respect to PREM. The black lines show the 410 and the $660 \mathrm{~km}$ discontinuities. 


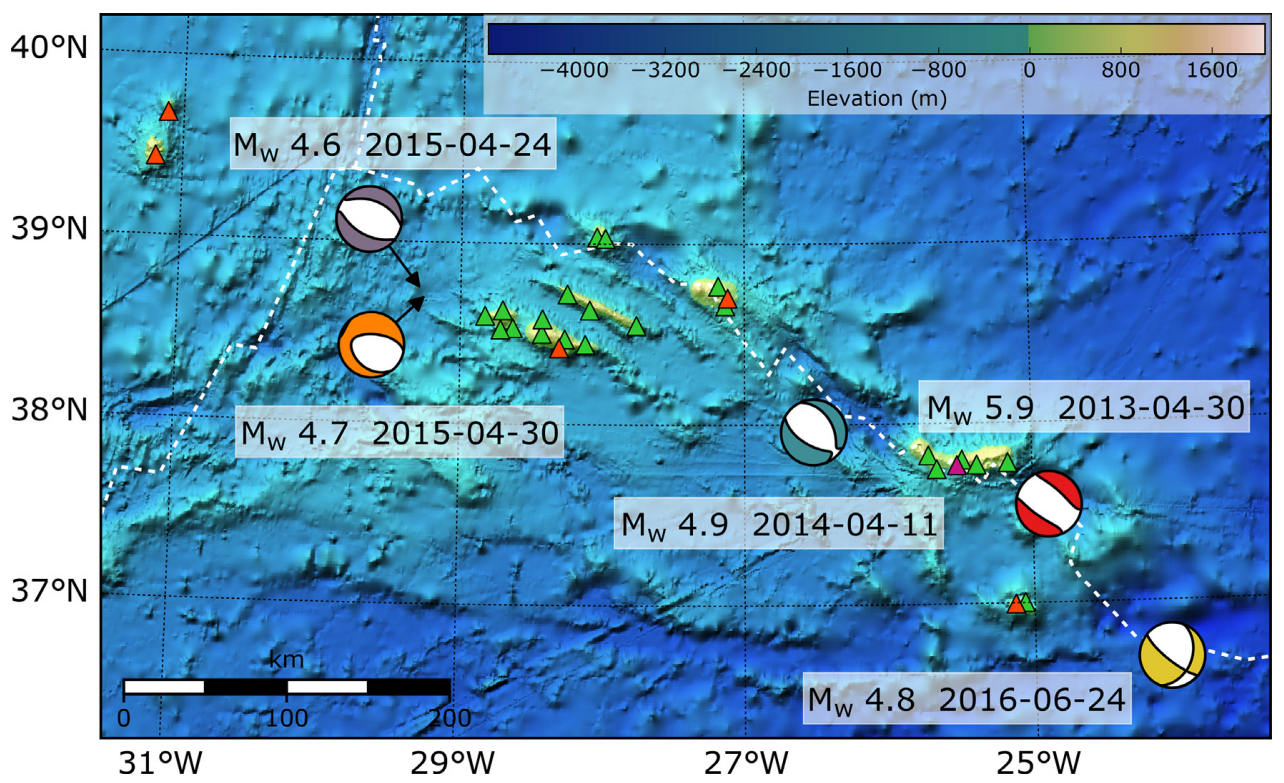

Figure 4. Station distribution in the Azores islands and moment tensor solutions of the earthquakes studied. The earthquake focal mechanisms shown correspond to the solution of the 1-D modelling obtained in this study using the Earth model P-S COSEAa (see Section 3.1.1). The stations are represented by triangles, while the earthquake locations are marked by the respective moment tensor solution. The GSN station CMLA is marked by a magenta triangle. The stations of the temporary COSEA network [used in the receiver function study of Silveira et al. (2010)] are represented by red triangles, whereas IPMA's stations are represented by green triangles. Plate boundaries in dashed white are from Bird (2003).

( $\left.M_{\mathrm{w}} 5.9\right), 2014$ April $11\left(M_{\mathrm{w}} 4.9\right), 2015$ April $24\left(M_{\mathrm{w}} 4.6\right), 2015$ April $30\left(M_{\mathrm{w}} 4.7\right)$, and 2016 June $24\left(M_{\mathrm{w}} 4.8\right)$ earthquakes. The spatial distribution of the earthquake locations obtained by IPMA is shown in Fig. 4, with all events exhibiting a dominantly normal faulting mechanism.

There are no reports of damage for any of these events. The $M_{\mathrm{W}}$ 5.9 earthquake was felt on São Miguel and the surrounding islands with a maximum intensity of $V$ on the Modified Mercalli Intensity Scale (USGS 2017).

\subsection{Local seismic data}

A permanent seismic network in the Azores islands is maintained and has been substantially enlarged since 2008 by IPMA, whereby over 14 new broad-band stations have been installed in the various islands (Table S1, Supporting Information). An overview of all the broad-band stations used in this study can be found in Fig. 4; given the geometry of the archipelago, the station distribution is nonuniform. In particular, the azimuthal coverage can be very poor depending on the event's location, such as for the two earthquakes in 2015 considered in this study (Fig. 4), for which all the stations are located to the east and south-east.

We obtained three-component seismic waveforms from IPMA for all five events and for all the stations shown in Fig. 4. The data for the four events with lowest magnitude are filtered using a Butterworth bandpass filter in the 12.5-20.0 s period range (Table 1). The period range of $16.7-33.3 \mathrm{~s}$ is used to filter the data for the $M_{\mathrm{w}} 5.92013$ April 30 event due to its lower frequency content. We found that these filtering parameters led to good quality signals compatible with our modelling after testing different period ranges between 10 and $40 \mathrm{~s}$.

The seismic traces are windowed in order to isolate the main arrival's signal with a window length of $256 \mathrm{~s}$. We visually analyse the data and remove traces with a large data misfit $(m>1)$ which we cannot model with our approach. An example of comparison of data and synthetic seismograms is shown for the $M_{\mathrm{w}} 5.92013$ event in Fig. 5.

\subsection{Teleseismic data}

In our teleseismic source inversions of the $M_{\mathrm{w}} 5.92013$ April 30 event we use three-component data from the GSN (IU, II), Caribbean (CU), China (IC), Geoscope (G), Geofon (GE), and MedNet (MN) networks.

We filter all the data using a similar strategy to Weston et al. (2014) with Butterworth bandpass filters according to Table 1. Different time windows are used depending on the wave type (Table 1): (i) surface waves are windowed around the maximum of the envelope function, and (ii) body waves are windowed according to the phase onset estimated by a seismic traveltime calculator (TauP, Crotwell et al. 1999).

We select data from stations in the epicentral distance range of $40^{\circ}-140^{\circ}$ for surface waves, and of $30^{\circ}-90^{\circ}$ for body waves. These criteria are applied in order to reduce near-source effects and the overlapping of multiple orbit wave trains. We exclude outliers by removing data that show very large discrepancies to synthetics. We reject data with waveform misfit $m \geq 1$ using synthetics computed for the GCMT solution and when the amplitude ratio of real versus synthetic waveforms is larger than 2. It is crucial to ensure an even azimuthal distribution of stations to avoid bias due to concentrations of stations in nearby azimuths. Therefore only a single station is used per azimuthal interval of $5^{\circ}$. We select the station with threecomponent data with the highest signal-to-noise ratio in each $5^{\circ}$ azimuthal bin. This results in 39 teleseismic $P$ waves, 47 teleseismic $S$ waves, and 39 surface waves selected for the $M_{\mathrm{w}} 5.92013$ April 30 event (Fig. 6). 
Table 1. Overview of the filter range and window length used for the different seismic data sets. A zero-phase Butterworth bandpass filter of order 2 is used in all cases, except for the local data where a Butterworth bandpass filter of order 4 is used.

\begin{tabular}{lcc}
\hline & Filter range (s) & Window length (s) \\
\hline Local & $12.5-20.0$ & 256 \\
Local $\left(M_{\mathrm{w}} 5.9\right.$ 2013 event) & $16.7-33.3$ & 256 \\
Teleseismic $P$ waves $\left(M_{\mathrm{w}} 5.92013\right.$ event) & $25-60$ & 120 \\
Teleseismic $S$ waves $\left(M_{\mathrm{w}} 5.92013\right.$ event) & $25-100$ & 150 \\
Teleseismic surface waves $\left(M_{\mathrm{w}} 5.9\right.$ 2013 event) & $125-180$ & 1000 \\
Regional $P$ waves $\left(M_{\mathrm{w}} 5.92013\right.$ event) & $15-40$ & 85 \\
Regional surface waves $\left(M_{\mathrm{w}} 5.92013\right.$ event) & $25-80$ & 190 \\
\hline
\end{tabular}

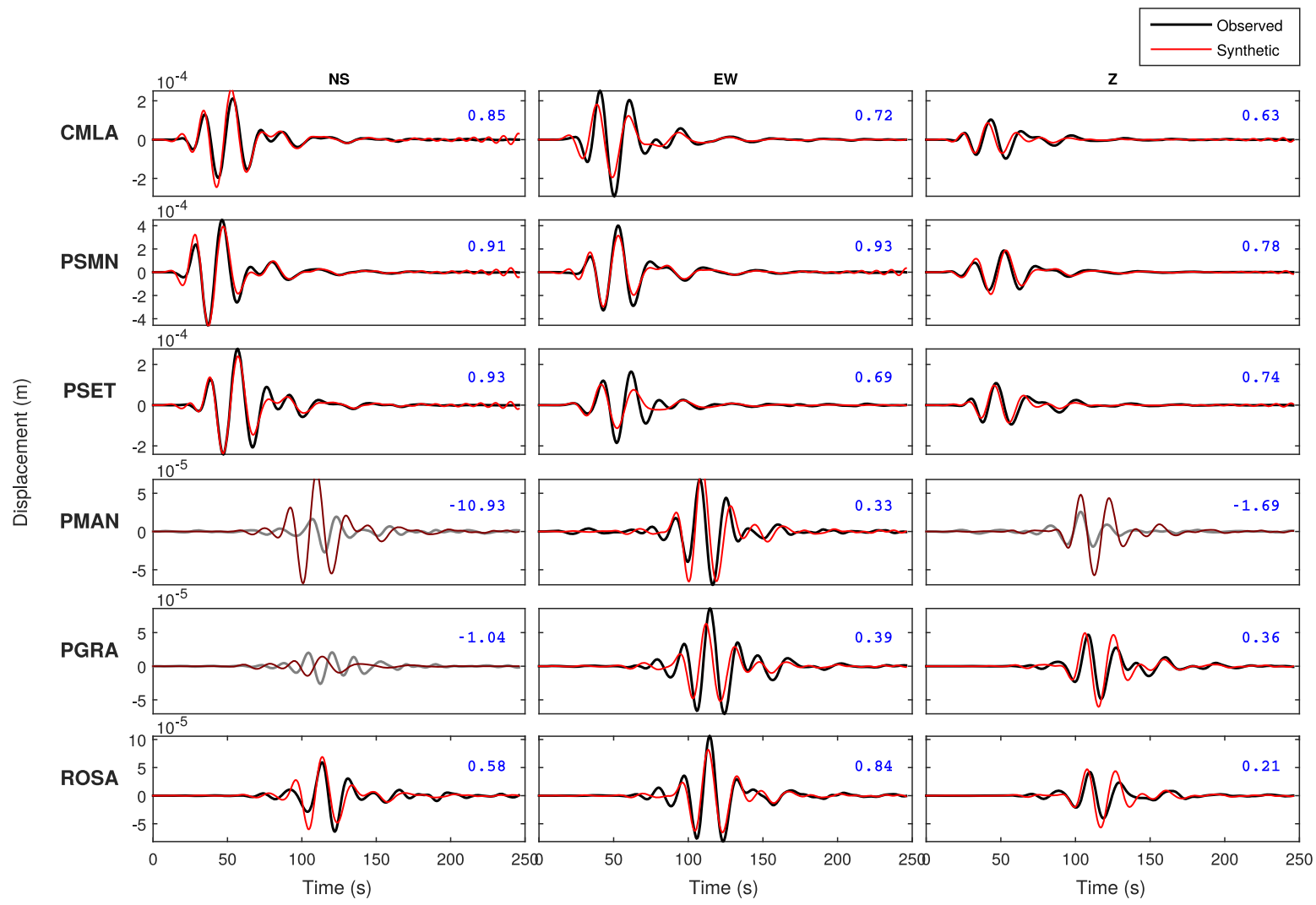

Figure 5. Local waveform examples for the 2013 April $30 M_{\mathrm{W}} 5.9$ Povoação basin earthquake. Comparison of the observed waveforms (black) with the theoretical seismograms (red) for six three-component stations in the Azores. The synthetic seismograms are computed for source parameters obtained in this study using the velocity model P-S RF COSEAa (see Section 3.1.1). The blue numbers correspond to the variance reduction. Traces in grey are not used in the inversion procedure due to their negative variance reduction.

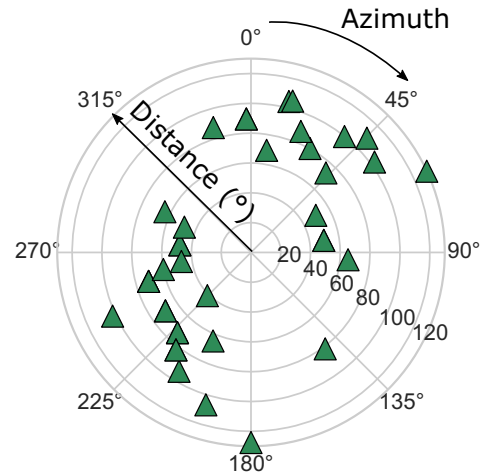

Tele. Surface waves

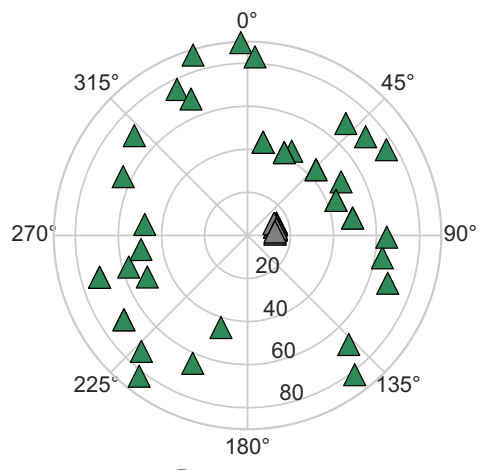

P-waves

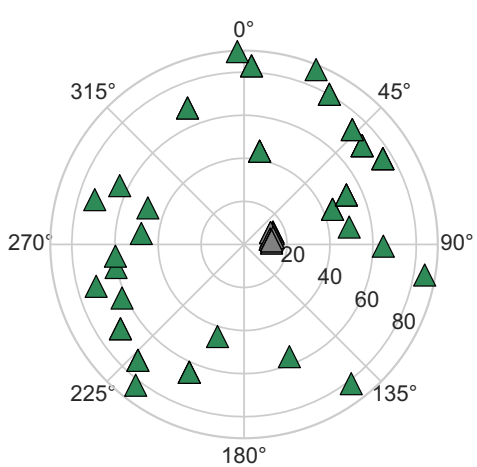

S-waves / Reg. Surface waves

Figure 6. Station distribution for the $M_{\mathrm{w}} 5.92013$ April 30 event. The stations are plotted as a function of azimuth and distance from the epicentre. Left: teleseismic surface waves (green triangles). Middle: regional (grey triangles) and teleseismic $P$ waves (green triangles). Right: regional surface waves (gray triangles) and teleseismic $S$ waves (green triangles). 


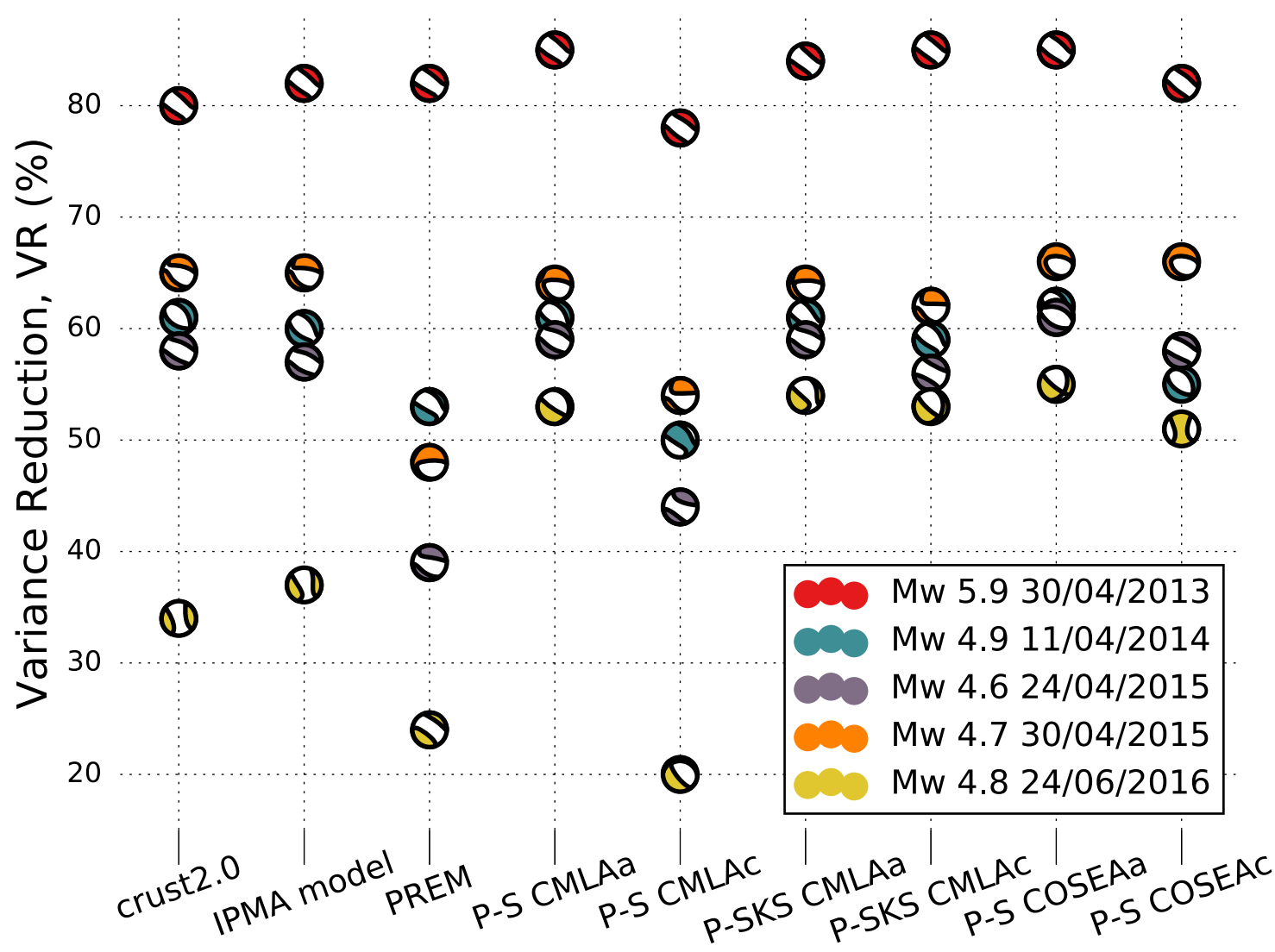

Figure 7. Variance reduction (VR $=1-m$, with $m$ being the $\mathrm{L}_{2}$-norm misfit) obtained from the inversions of the five earthquakes for each earth model shown in Fig. 2. Different colours are used to distinguish the five earthquakes.

\subsection{Regional data as a validation tool}

In addition to the local data set, we have access to seismic data from mainland Portugal. This regional data set is not used in the inversion process in order to avoid an azimuthal bias (Fig. 6). Nevertheless, we benefit from these regional waveforms by comparing them with synthetic waveforms computed for the source models determined in our study as a useful, independent way of validating our source models.

We filter and window the data using the parameters in Table 1. The validation comparisons can be found in Section 5.2.

\section{RESULTS}

\subsection{1-D modelling of local seismic data}

Fig. 7 compares results of 1-D local data source inversions obtained for all five earthquakes. It is clear that the variance reduction $(\mathrm{VR}=$ $1-m$, a measure for the quality of the inversions) depends on the Earth model, on the event's magnitude, and on the stations' distribution. When varying the 1-D Earth model, the source mechanism remains relatively stable for the events with the highest variance reduction values. Events with low variance reduction show stronger variability in the solutions, notably the most recent earthquake with $M_{\mathrm{w}} 4.8$ on 2016 June 24 . This is due to the data's low signal-to-noise ratio combined with an uneven station configuration, with all the local stations used in the inversions being located to the NW of the event's epicentre.
The models PREM and P-S CMLAc lead to the poorest data fits for all events studied, while the model P-S COSEAa performs best in all five cases.

Fig. 8 shows that the 1-D Earth model used in the inversions can have a very strong influence on the retrieved fault strike, dip, rake, and double-couple component. We observe clear outliers in the solutions associated with lower variance reduction values such as for the $M_{\mathrm{w}} 4.62015$ April 24 event. These five outliers are characterized by substantially lower variance reduction values than the other moment tensor solutions for the same event. In addition, outlier solutions show source parameters with large differences to the other solutions. The variation of the fault parameters lends insight into source parameter errors due to uncertainty in Earth structure. Excluding the aforementioned outliers, the fault strike varies by $15^{\circ}$ to $30^{\circ}$, the fault dip between $5^{\circ}$ and $20^{\circ}$, and the fault rake between $20^{\circ}$ and $60^{\circ}$ between all the 1-D Earth models used in the inversions. The corresponding Fig. S3 for centroid time-shift, centroid depth, and seismic moment is presented in the Supporting Information. The centroid time-shift to the origin time varies for the different solutions approximately by $2 \mathrm{~s}$, the seismic moment by 50 per cent, and the centroid depth by about $10 \mathrm{~km}$, excluding the outliers mentioned above. The double-couple component may be as small as 10 per cent, depending on the earthquake (Fig. 8). We see a tendency of small double-couple components for the Earth models with poorest data fits for a given event. Several studies have highlighted that modelling errors may lead to artificial non-doublecomponents (e.g. Henry et al. 2002; Ferreira et al. 2011). Hence, the observed low double-couple components of the solutions with poorest data fit may be due to unmodelled effects. Nevertheless, 


\begin{tabular}{|llllll|}
\hline$\nabla$ crust2.0 & $\star$ PREM & $\downarrow$ P-S CMLAC & P-SKS CMLAc \\
$\times$ IPMA & $\downarrow$ P-S CMLAa & & P-SKS CMLAa & $\star$ P-S COSEAa & \\
\hline
\end{tabular}
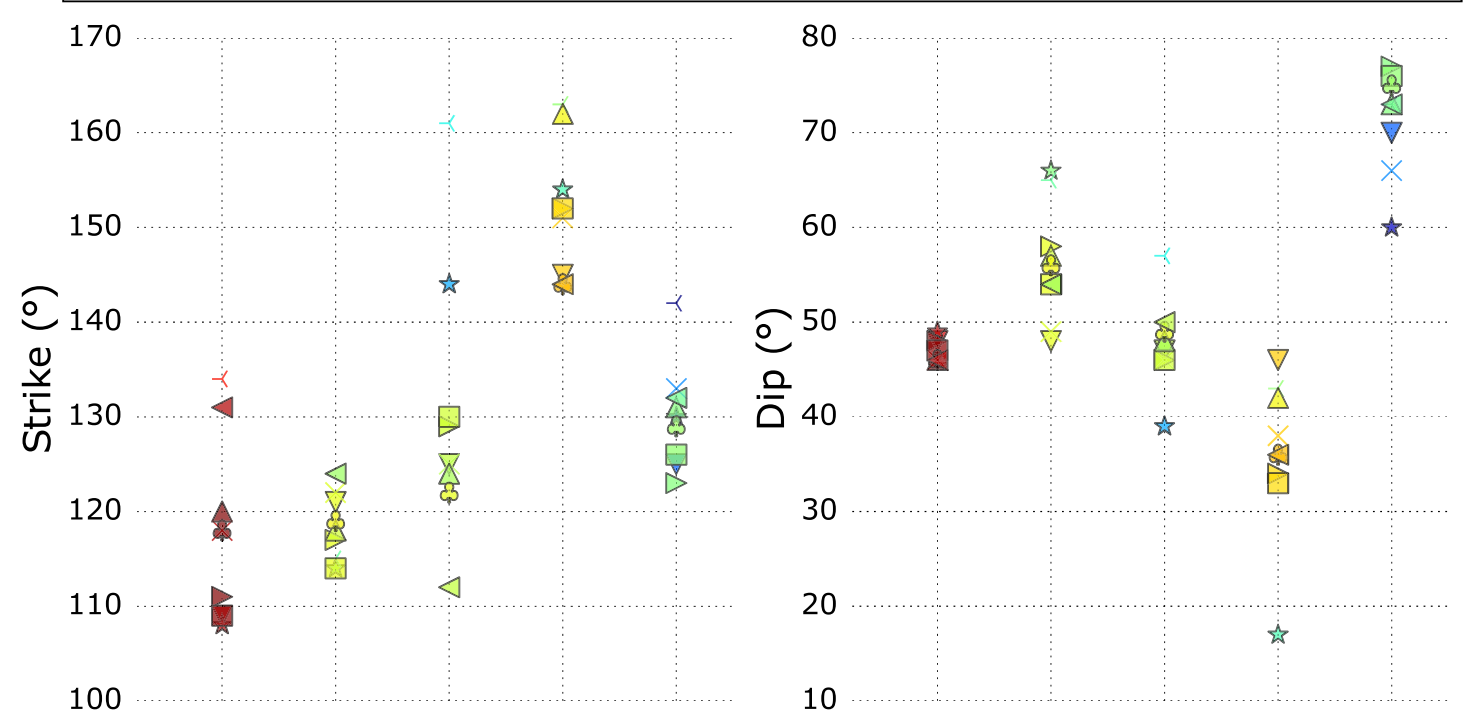

$-80$

$-72$

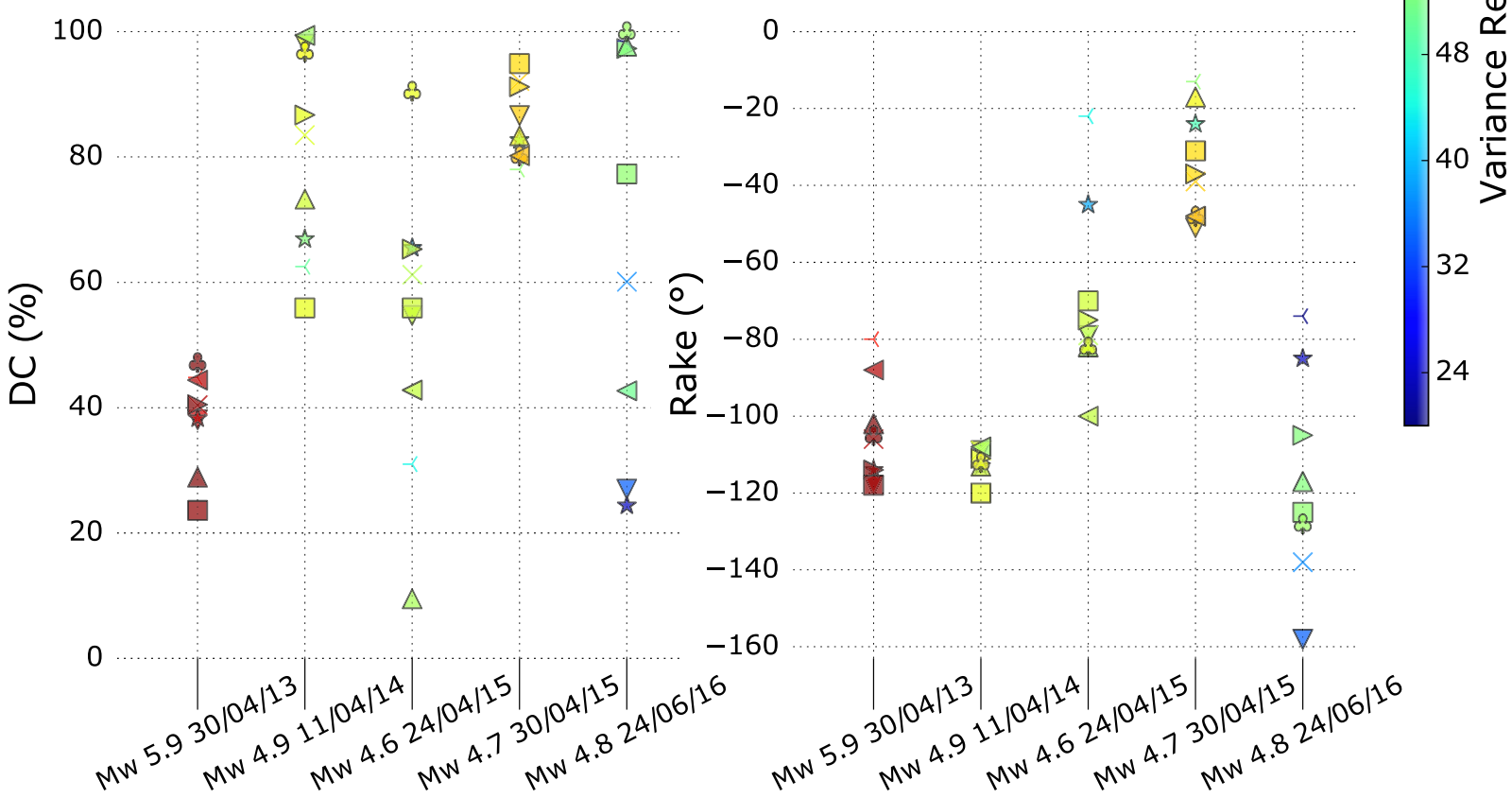

Figure 8. Comparison of the inversion results for the five earthquakes studied and for the nine earth models used in the inversions (see Fig. 2). We present comparisons for fault strike (top left), fault dip (top right), double-couple component (bottom left) and fault rake (bottom right). The fault parameters for the moment tensor solutions are colour-coded according to their variance reduction and marked by different symbols according to the Earth model used in the inversion.

the $M_{\mathrm{w}} 5.92013$ April 30 earthquake shows low double-couple components for every tested model, not exceeding 50 percent. Thus, such low double-couple component may be real.

\subsection{The $M_{\text {w }} 5.92013$ April 30 Povoação basin earthquake, SW of São Miguel island}

The largest magnitude $M_{\mathrm{w}} 5.92013$ April 30 event deserves a more detailed investigation due to the observed non-double-couple component and possible source complexity. Therefore, it is the only event studied with stations at teleseismic distance and modelled with 3-D Earth models.

We test two different locations in our moment tensor inversions using 3-D Earth models: (i) the hypocentral location from the local seismic service IPMA, and (ii) the centroid location from the GCMT catalogue. As explained in Section 3.2, in order to stabilize the inversions the depth is fixed to $12 \mathrm{~km}$, which corresponds to the depth of the preferred solutions for this event from the 1-D modelling (Fig. S3, Supporting Information). The IPMA hypocentre and the GCMT centroid are $25 \mathrm{~km}$ apart. The IPMA hypocentre seems to be more accurate because it leads to smaller local data 
misfits than when using the GCMT centroid (Table 2). We note that although the hypocentre and the centroid are not directly comparable, a distance of $25 \mathrm{~km}$ is much larger than the expected difference in hypocentre-centroid location for an $M_{\mathrm{w}} 5.9$ event (e.g. Smith \& Ekström 1997), and is consistent with previously reported errors in GCMT centroid locations (Weston et al. 2011, 2012).

\subsubsection{Inversion of local data with 3-D modelling}

Fig. 9 shows the results of our local data moment tensor inversions using a variety of 3-D Earth models, for the IPMA hypocentre (blue) and GCMT (red) centroid locations. We find that using the IPMA hypocentre location generally leads to larger variance reductions than when using the GCMT centroid location (Table 2). Moreover, when using the IPMA location, the retrieved source parameters are similar to the best-fitting solutions obtained in the 1-D modelling of the local data. Using the GCMT location leads to substantially different source parameters. Thus, the earthquake location used in the inversions has a larger impact on the inversion results than changing the 3-D Earth model. This is due to the use of local data, which are strongly sensitive to traveltime differences introduced by different locations.

\subsubsection{Uncertainties in local data inversions due to data variability}

In order to quantify the uncertainties in our 3-D local data inversions due to data variability, we perform bootstrapping tests. We carry out moment tensor inversions excluding one seismic trace in each inversion, and examine the ensemble of the solutions obtained.

Fig. 9 shows the results of the bootstrapping tests for moment tensor inversions of local data using 1-D (1-D Local BS) and 3-D (3-D Local BS) Earth models. In both cases, these tests lead to a variability of $\sim 15^{\circ}$ in strike and dip, $25^{\circ}$ in rake, and $10-15$ per cent in double-couple component. Table S2 in the Supporting Information shows the results obtained when a volumetric change is allowed in the inversions. A variability of 6-13 per cent of volumetric component is observed. Importantly, allowing such volumetric change in the moment tensor inversions does not have a substantial influence on the retrieved source parameters.

Both bootstrapping tests show a substantial variability in the retrieved fault parameters, which demonstrates that the local seismograms from the closest stations (CMLA and PSMN) are crucial for the stability of the inversions. Excluding the north component data from station PSMN leads to a significantly smaller fault dip angle and higher seismic moment than when it is included in the inversions. On the other hand, excluding the east component seismogram from station CMLA in the inversions leads to smaller fault strike and fault rake angles than in the other solutions (Table S2 in the Supporting Information). The misfit function used is strongly sensitive to seismic traces with high amplitudes and thus the stations closest to the hypocentre have a strong influence on the inversions. Nevertheless, the median values of the source parameters obtained from the bootstrapping tests match the parameters obtained in the inversions using all the available local data (Fig. S8, Supporting Information).

\subsubsection{Teleseismic and joint data inversions with 3-D modelling}

Fig. 9, Table 2, and Fig. S4 in the Supporting Information show the results of our inversions using the individual data sets as well

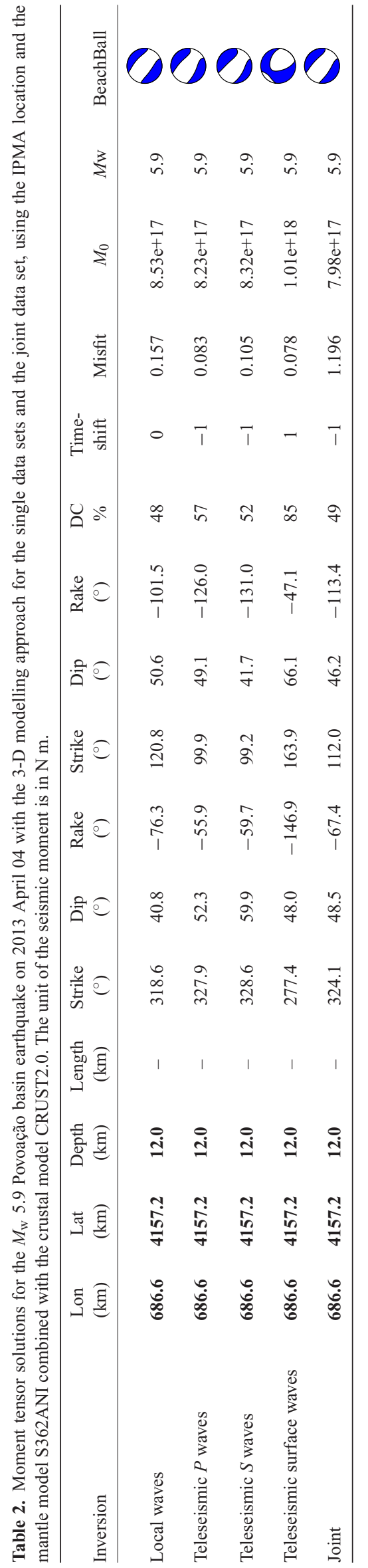



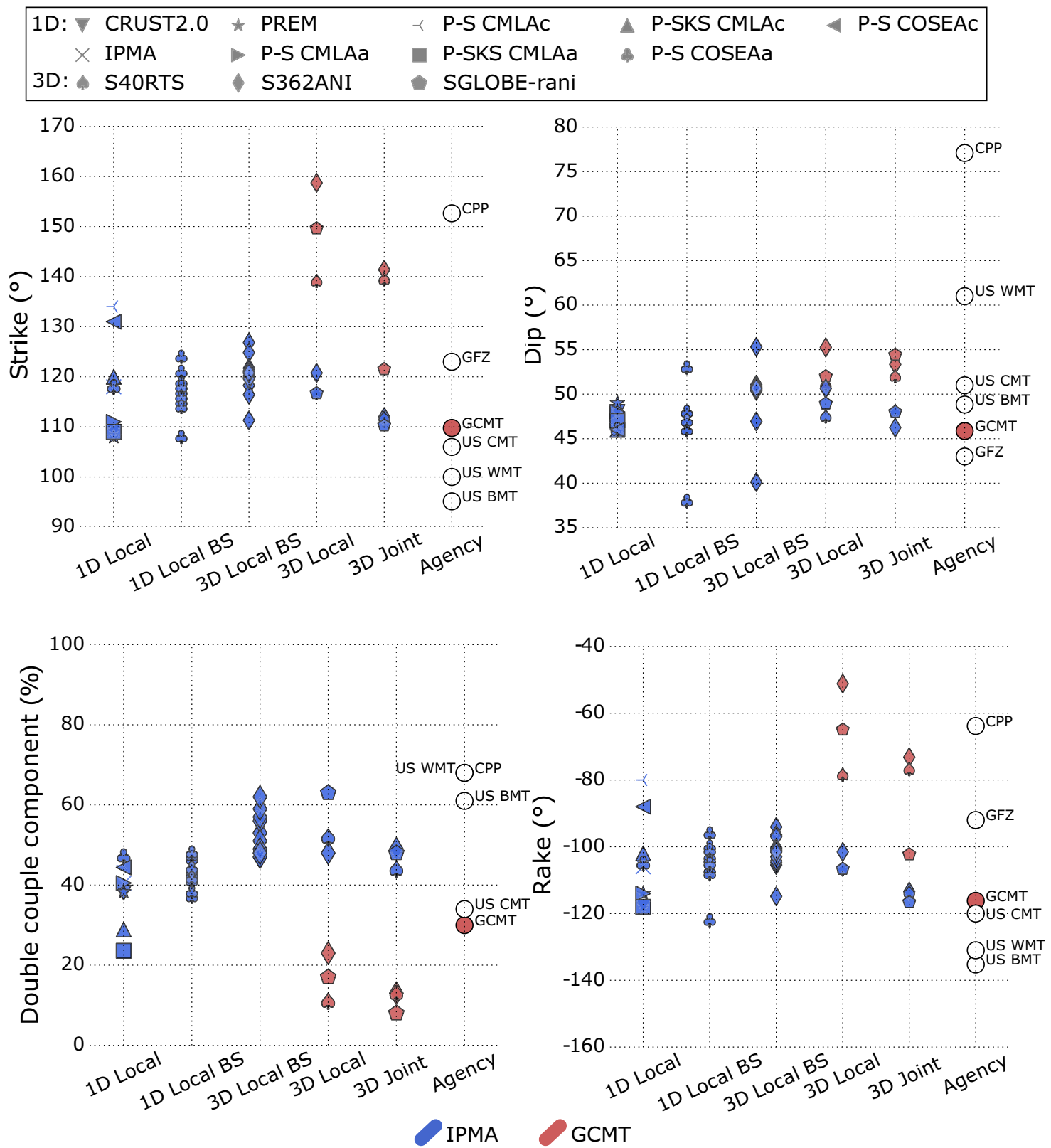

Figure 9. Comparison of the results from the different modelling approaches used in this study with moment tensor solutions from various seismic agencies. The results of the local data 1-D modelling are marked by a different symbol for each of the nine 1-D earth models used. '1-D Local BS' labels the results from the bootstrapping test for the 1-D modelling, performed with the best-fitting Earth model P-S RF COSEAa. '3-D Local BS' is the corresponding labelling for the bootstrapping test for the modelling using the 3-D mantle model S362ANI. The 3-D modelling results are marked by different symbols according to the mantle model used in the inversion. The fault parameters are shown for two different modelling approaches: using local data alone ('Local') and jointly with teleseismic $P, S$, and surface waves ('Joint'). Circles illustrate the moment tensor solutions reported by various seismic agencies (see Fig. 13 for an explanation of the agencies used). Different colours denote two different locations: blue for IPMA and red for GCMT. The fault parameters are shown for fault strike (top left), fault dip (top right), fault rake (bottom right) and double-couple component (bottom left). The GFZ agency imposes a double-couple solution in their inversions; thus, it is excluded from the plot showing the double-couple component.

as those from the joint inversion of teleseismic body, surface, and local waveforms (Fig. 9 and Table 2). Figs 10 and 11 show that the joint inversion solution explains the various seismic data sets well. The best-fitting waveforms are the teleseismic $P$ and surface waves, both with a misfit of $m=0.08$. The teleseismic $S$ waves show a misfit value of $m=0.11$, while the local seismic data have a misfit value of $m=0.16$ with an overall good visual fit of the observed waveforms. In addition, Fig. 12 shows that this solution also fits well independent regional seismic waveforms that were not used in the inversions.

As seen previously in the inversions of local data alone, it is clear that the results depend strongly on the earthquake location used. Using IPMA's hypocentre leads to a lower variability in the retrieved source parameters, to a much better agreement with results from local data inversions (Fig. 9) and to lower data misfits than using the GCMT centroid (Table 3). Changing the 3-D Earth model 
Local waveforms
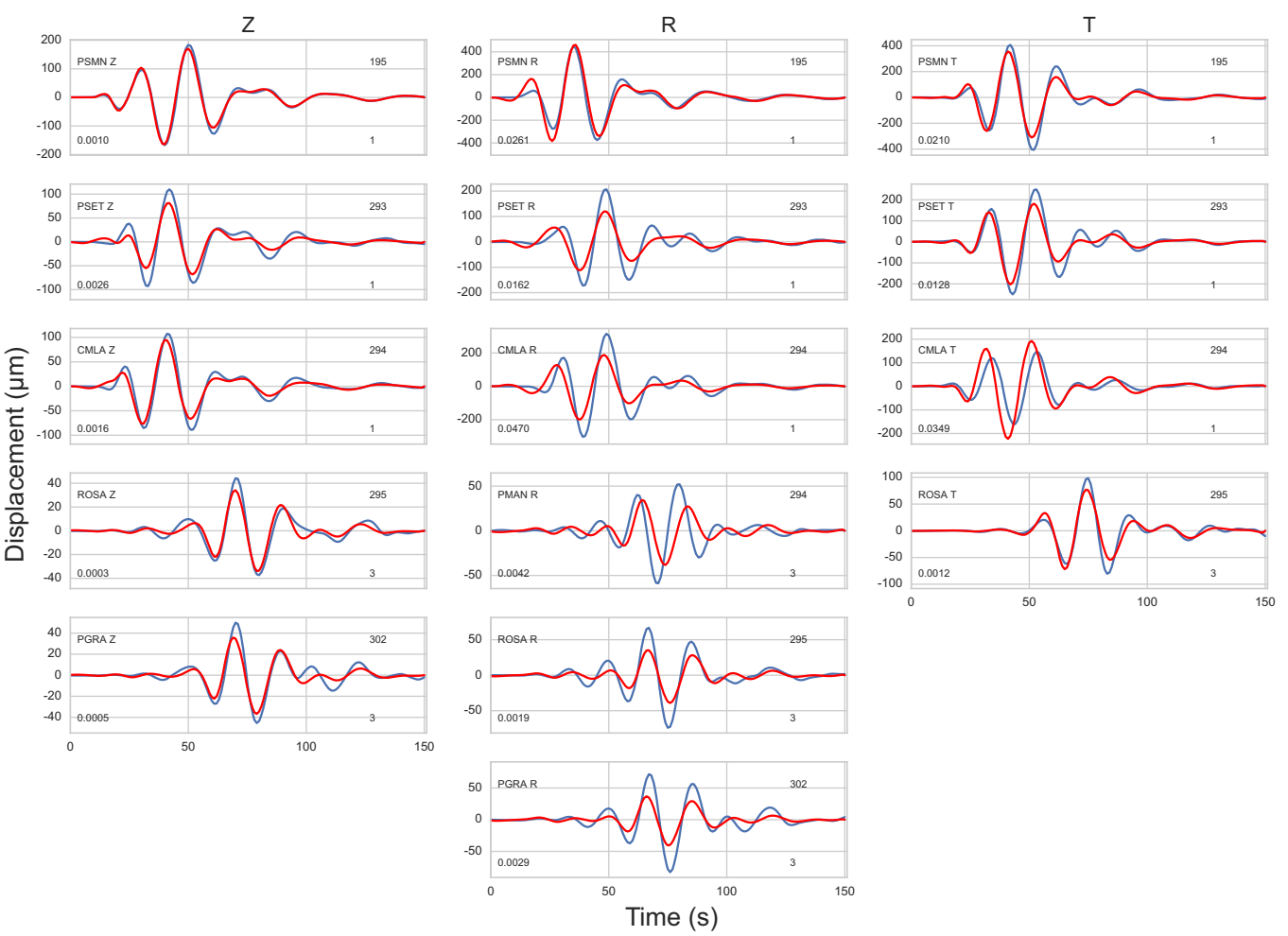

Figure 10. Waveforms of local and teleseismic surface wave data for the $M_{\mathrm{W}} 5.92013$ April 30 earthquake. Top: local waveforms; and bottom: surface waves. Comparison of the recorded waveforms (blue) with the forward modelled waveforms (red) for the solution obtained from the joint inversion of local and teleseismic data. The inversion results shown here are based on the crustal velocity model CRUST2.0 and the mantle model S362ANI, using the IPMA location as a centroid. 
Teleseismic P-waves

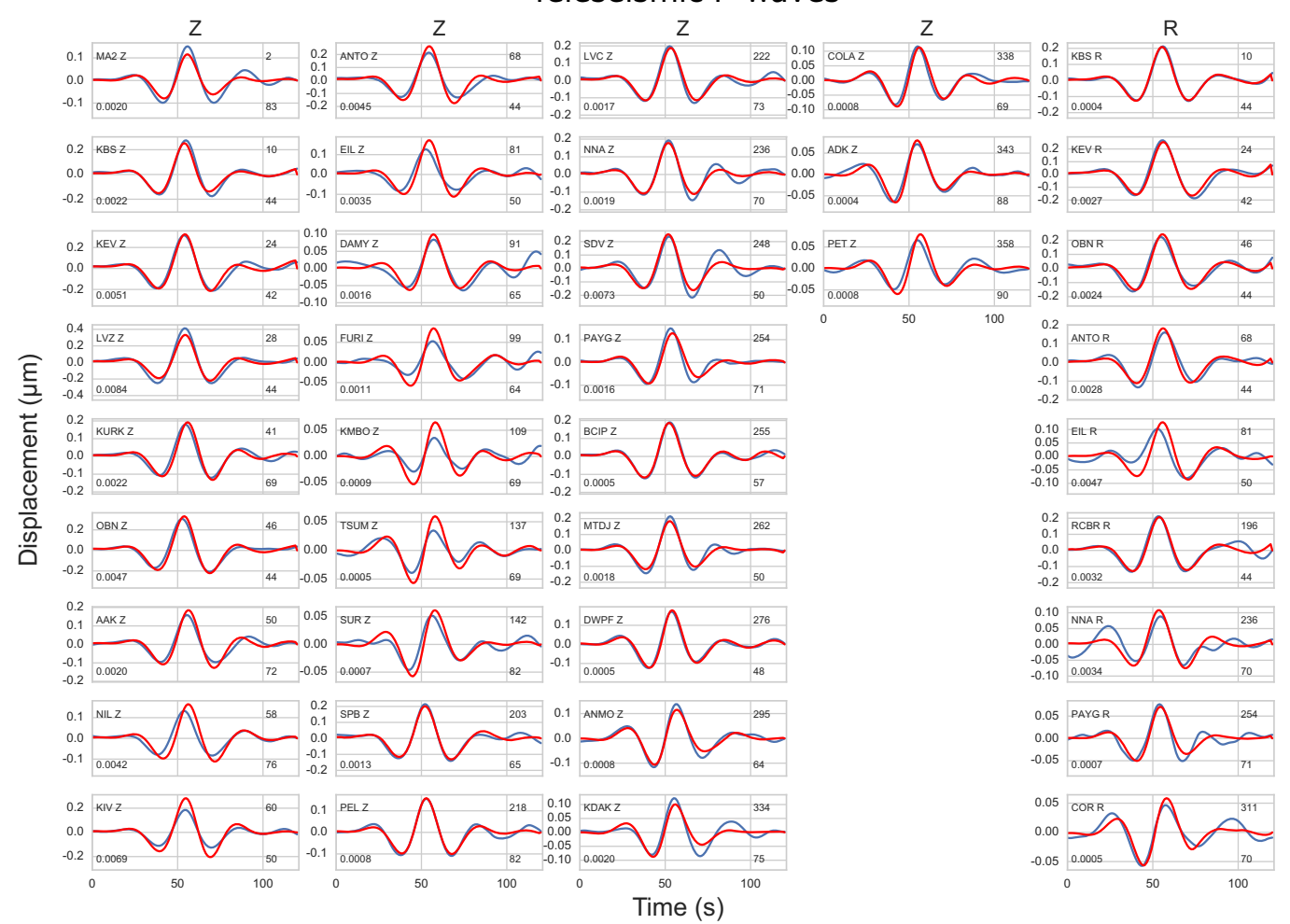

\section{Teleseismic S-waves}

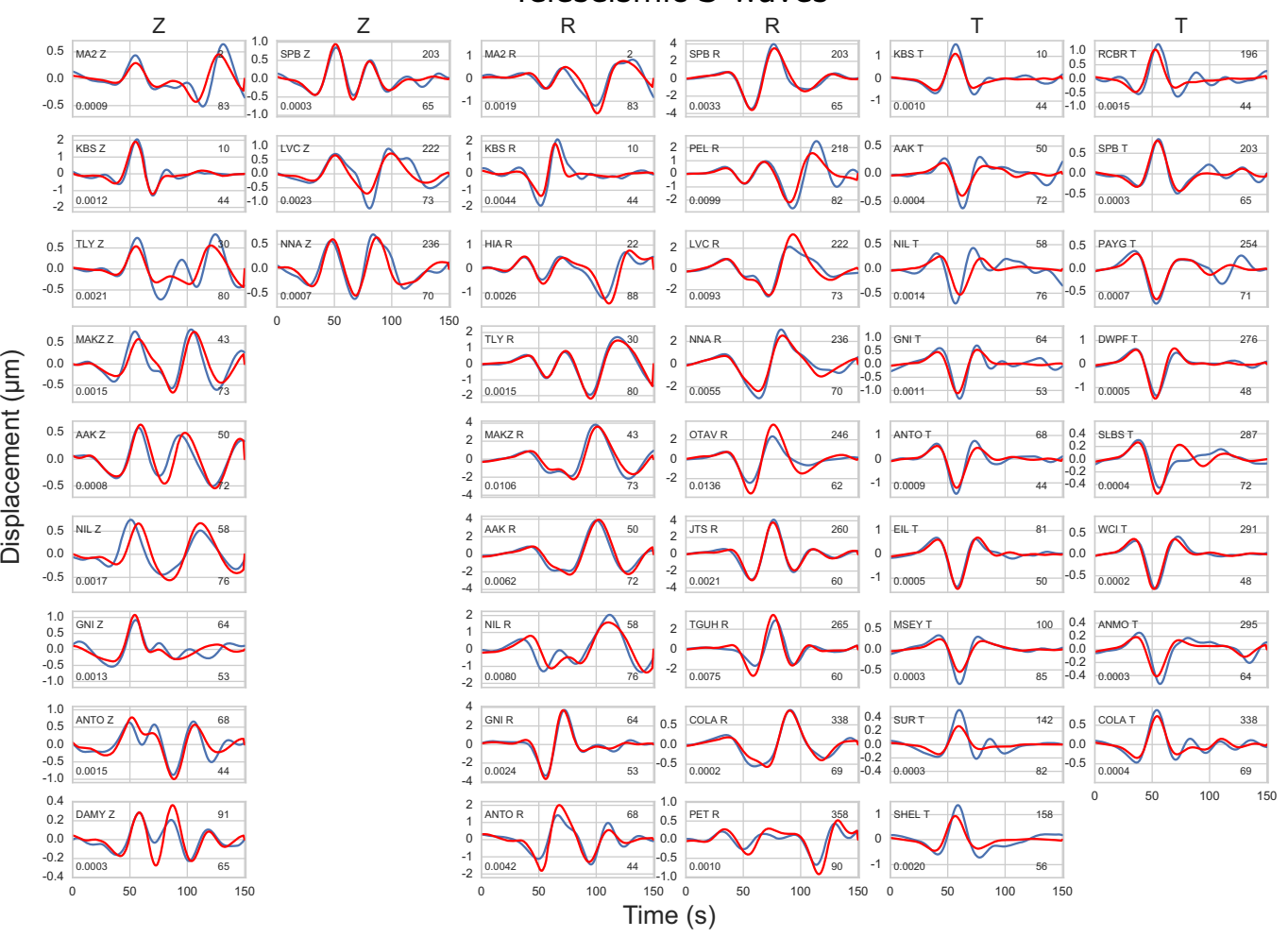

Figure 11. Waveforms of teleseismic body wave data for the $M_{\mathrm{w}} 5.92013$ April 30 earthquake. Top: teleseismic $P$ waves and bottom: teleseismic $S$ waves. Comparison of the recorded waveforms (blue) with the forward modelled waveforms (red) for the solution obtained from the joint inversion of local and teleseismic data. The inversion results shown here are based on the crustal velocity model CRUST2.0 and the mantle model S362ANI, using the IPMA location as a centroid. 

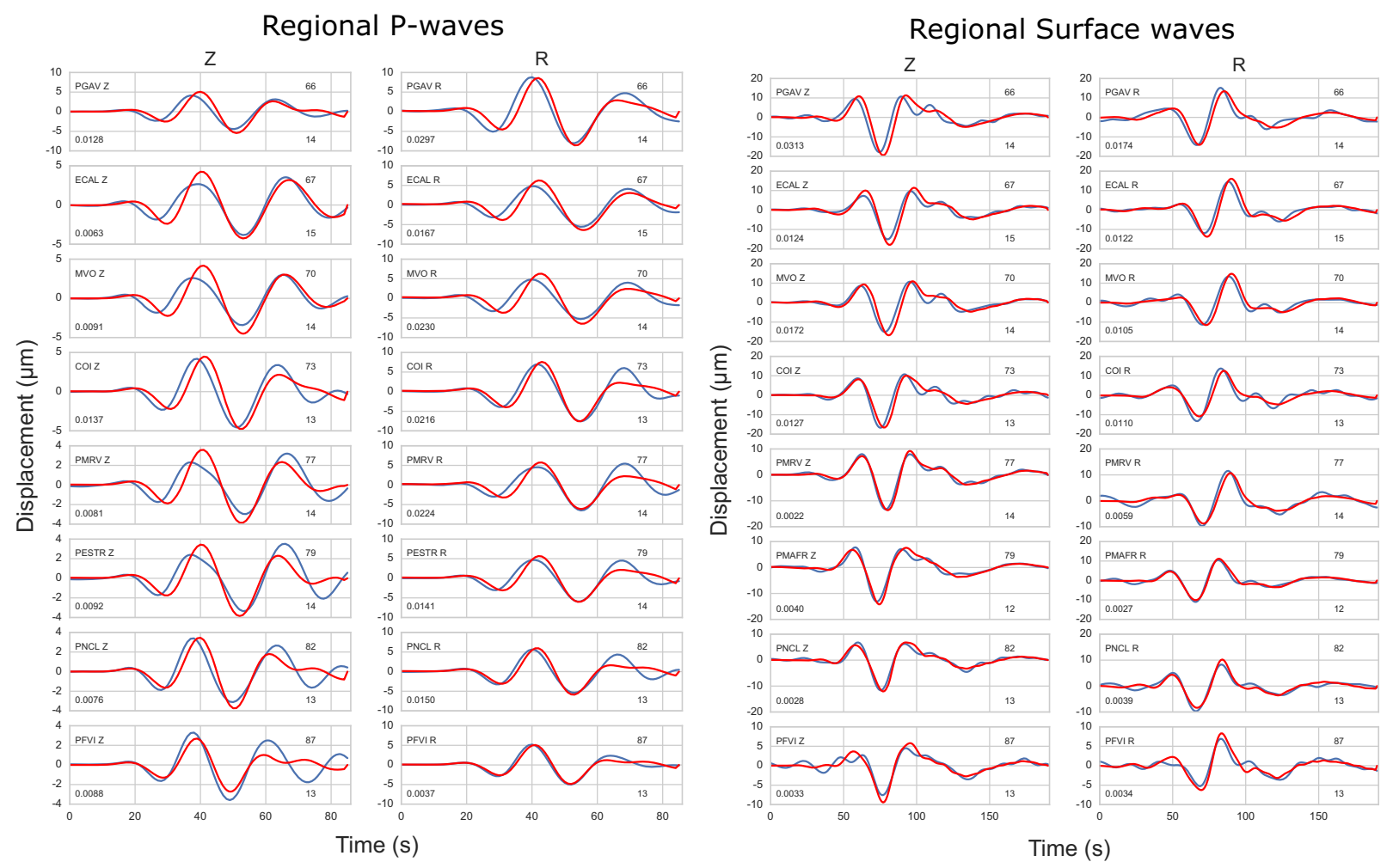

Figure 12. Waveforms of regional waveforms for the $M_{\mathrm{w}} 5.92013$ April 30 earthquake. Left: regional $P$ waves; and right: regional surface waves. Comparison of the recorded waveforms (blue) with the forward modelled waveforms (red) for the solution obtained from the joint inversion of local and teleseismic data. The inversion results shown here are based on the crustal velocity model CRUST2.0 and the mantle model S362ANI, using the IPMA location as a centroid. These waveforms have not been used in the inversion procedure.

Table 3. $L_{2}$-norm misfits of the inversion results for the four different data sets $(k)$ used (local, teleseismic surface waves, $P$ and $S$ waves), for the six combinations of Earth models and locations. The lowest misfit for each data set $\left(\min \left(m_{k}\right)\right)$ is marked in bold. The last column presents the normalized average misfit $m_{\text {norm }}=\frac{1}{4} \sum_{k=1}^{4} \frac{m_{k}}{\min \left(m_{k}\right)}$.

\begin{tabular}{|c|c|c|c|c|c|c|}
\hline Location & Earth model & $m_{\text {Local }}$ & $m_{\text {Surface }}$ & $m_{\text {Tele } P}$ & $m_{\mathrm{Tele} S}$ & $m_{\text {norm }}$ \\
\hline IPMA & S362ANI & 0.16 & 0.08 & 0.08 & 0.11 & 1.16 \\
\hline IPMA & S40RTS & 0.15 & 0.09 & 0.08 & 0.16 & 1.32 \\
\hline IPMA & SGLOBE-rani & 0.19 & 0.08 & 0.09 & 0.09 & 1.18 \\
\hline GCMT & S40RTS & 0.33 & 0.06 & 0.15 & 0.21 & 1.85 \\
\hline GCMT & SGLOBE-rani & 0.32 & 0.06 & 0.15 & 0.11 & 1.56 \\
\hline
\end{tabular}

used in the source inversions has a lower impact on the retrieved source parameters and on the data fit than changing the earthquake's location (Fig. 9 and Table 3). For a given earthquake location, the three mantle models used in the inversions lead to relatively similar data misfits, with S362ANI and SGLOBE-rani achieving slightly lower misfit values than S40RTS (Table 3).

Considering the results based on IPMA's hypocentre, there is overall a good agreement between the joint inversion solutions and the results from the 1-D and 3-D local data inversions (Fig. 9), with differences in strike, dip, and rake not exceeding $\sim 10^{\circ}$. The variability of earthquake source parameters obtained in the joint inversions is generally smaller compared to the single data set inversions. Therefore, joint inversion of local and teleseismic data can reduce the uncertainty of the single data set inversions.

Figs S6 and S7 in the Supporting Information show plots of the trade-offs between the source parameters explored in our Monte Carlo inversions for 3-D local data and for 3-D joint source inversions. Overall, the joint inversion solutions are more tightly clustered than the local data solutions, notably for rake, strike, and dip angles.

\section{DISCUSSION}

The study of oceanic earthquakes can be challenging due to poor seismic station coverage, combined with insufficient knowledge about the Earth structure in those areas. In this study, we investigated five moderate magnitude events in the Azores islands recorded by local stations and using local models of the Earth structure of the region. Our findings demonstrate that data variability, the centroid location, and the Earth model used in the seismic forward modelling can have a significant impact on the source parameters, but these uncertainties are not always assessed in routine moment tensor inversions. An example is the regional study of the 2002 February 14 $M_{\mathrm{W}} 4.8$ earthquake in Udine, Northern Italy, where the 1-D crustal model used in the source inversions is perturbed by up to 30 per cent and the moment tensor is still well resolved (Š́lený 2004). More 
recently, Scognamiglio et al. (2016) reported a variability of fault strike, dip, and rake of about $10^{\circ}$ in a study of the $M_{\mathrm{w}} 5.9$ Emilia (Po Plain, Italy) 2012 earthquake, when testing five different 1-D Earth models and one 3-D structure model. Here, changes in the 1-D and 3-D Earth models used in the source inversions led to a larger variability in the retrieved fault parameters than in these studies $\left(15^{\circ}-30^{\circ}\right.$ in fault strike, $5^{\circ}-20^{\circ}$ in fault dip, and $20^{\circ}-60^{\circ}$ in rake). The variability of the parameters in our study is also larger than the errors estimated by Weston et al. (2012) (strike $\sigma=12.7$, $\operatorname{dip} \sigma=14.6$, rake $\sigma=16.4$ ) when comparing earthquake source parameters determined using InSAR with those obtained from seismic data. Likely, our variability in source parameters is larger than in previous studies due to the smaller magnitude and more irregular station coverage of the earthquakes studied here. Comparing the various 1-D Earth models used, we find that some of the 1-D Earth models of the region obtained from the analysis of receiver function data (Silveira et al. 2010) lead to a slightly improved data fit of local data compared to the region's 1-D model based on active seismic surveys currently used by IPMA. This shows that velocity profiles from receiver function studies can help constrain seismic moment tensors, particularly in regions with limited data coverage where seismic tomography studies may be difficult.

We further analysed the $M_{\mathrm{w}} 5.92013$ April 30 earthquake that occurred in the Povoação basin, SW of the São Miguel island using local, regional, and teleseismic data. We found that the earthquake's centroid location has a significant impact on the moment tensor inversions. Using the hypocentre reported by IPMA, which is based on local seismic data, leads to more stable solutions than the GCMT centroid, which is $\sim 25 \mathrm{~km}$ away from IPMA's hypocentre. This is consistent with the study of Weston et al. (2012), which reported global average errors in GCMT locations of $\sim 20 \mathrm{~km}$ and highlighted the higher accuracy of locations reported by local seismic agencies compared to global catalogues. Matias et al. (2007) also found substantial discrepancies between locations calculated using local data and those reported by global seismic agencies when studying the 1998 July 9 Faial sequence, in the Azores archipelago. We find that using the IPMA's hypocentre results in similar moment tensors obtained from teleseismic data to those retrieved using local data. This suggests that in oceanic regions where local seismic data are not available, teleseismic moment tensor inversions can be valuable if reasonable constraints on the earthquake location can be obtained from bathymetry information (Pan et al. 2002), macroseismic data, or other geological information. Moreover, we find that when using IPMA's location, the combination of local and teleseismic data in the inversions reduces the variability of the solutions and parameter trade-offs compared to local data inversions. Hence, teleseismic data can help stabilize the moment tensor inversions of oceanic earthquakes.

We found that all our moment tensor inversions lead to a persistent non-double component of $\sim 40-60$ per cent for the $M_{\mathrm{w}} 5.9$ event. In order to investigate its origin, we performed inversions allowing a volumetric change in the source and found a stable isotropic component of 6-13 per cent. For tectonic earthquakes, isotropic components may be due to the opening of non-planar faults normal to the fault plane (Julian et al. 1998; Ross et al. 2015), shear-tensile cracks (Julian et al. 1998), high fluid pressures in the crust (Vavryčuk 2002; Rössler et al. 2007) and changes of the elastic moduli due to the earthquake (Ben-Zion \& Ampuero 2009). Nevertheless, allowing a volumetric change in the source did not reduce substantially the non-double component of the event. As we ruled out the possibility of a volumetric change causing the low double-couple component, we speculate that geometrically complex faulting is responsible for

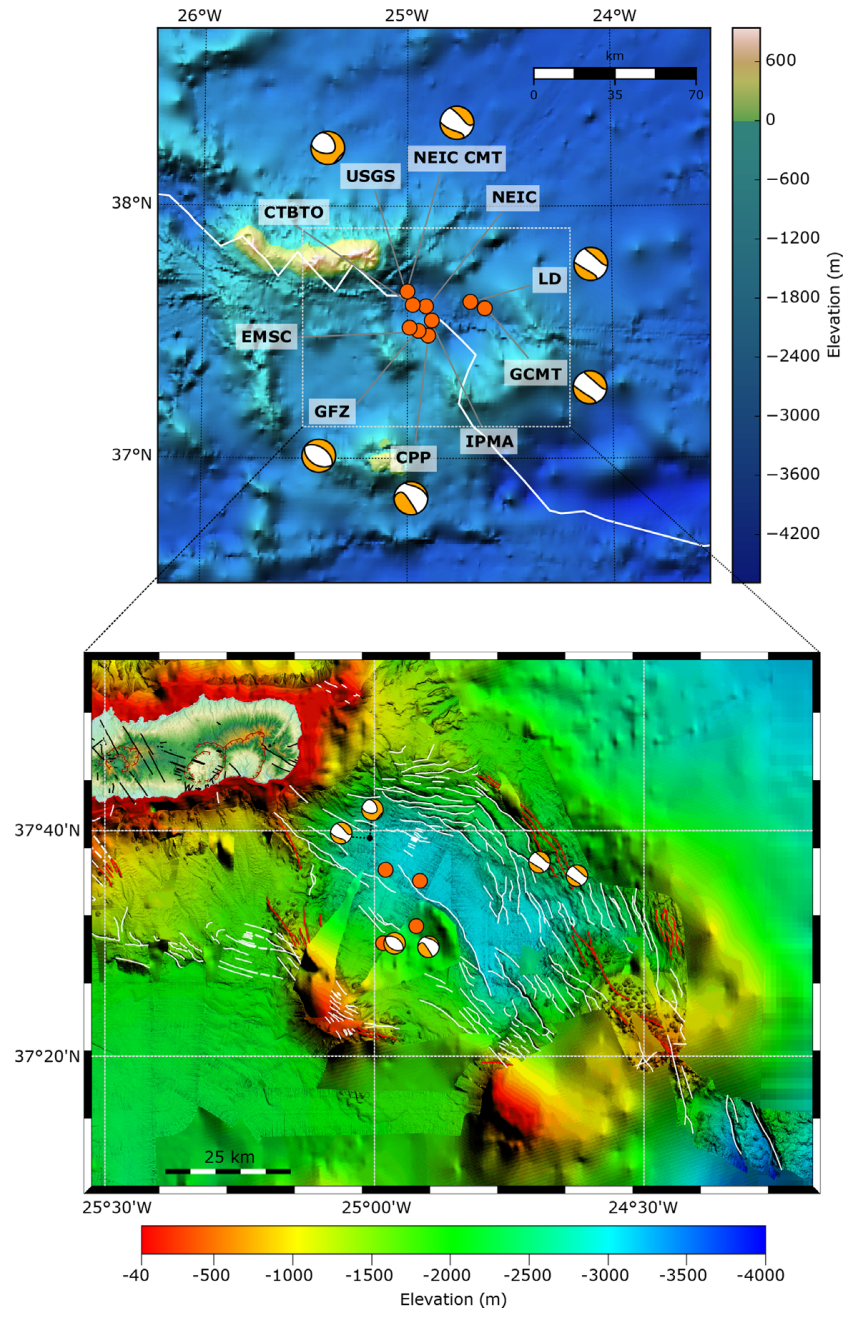

Figure 13. Epicentral and centroid locations for the Povoação basin earthquake with $M_{\mathrm{W}} 5.92013$ April 30. Top: the orange dots show seismic locations from NEIC (National Earthquake Information Center), CTBTO (Preparatory Commission for the Comprehensive Nuclear-Test-Ban Treaty Organization), IPMA (Instituto Português do Mar e da Atmosfera, Portuguese seismic service), EMSC (European-Mediterranean Seismological Centre) and centroid locations from US WMT (United States Geological Survey, W-Phase), US CMT (Lamont-Doherty Cooperative Seismographic Network, C-Phase), GCMT (Global Centroid-Moment-Tensor project), US BMT (National Earthquake Information Center, Body-Phase), GFZ (GFZ German Research Centre for Geosciences) and CPP (Jascha Polet, Department of Geological Sciences, Cal Poly Pomona, accessed via EMSC moment tensor database). The respective moment tensor solutions are shown where available. Plate boundaries in white are from Bird (2003). Bottom: same as in the top figure, but on a more detailed tectonic overview of the Povoação basin and surrounding structures provided by Weiß et al. (2015). The white lines are mapped faults and the red lines illustrate volcanic lineaments (after Weiß et al. 2015).

the observed substantial non-double component (Frohlich 1994). A detailed tectonic structure model produced by Weiß et al. (2015, Fig. 13) reveals the strong complexity of the Povoação basin. If we consider a rupture length of 14-20 km for this event based on earthquake scaling laws (Blaser et al. 2010) and the curved faults in Fig. 13 on the same scale, then the observed curvature of the faults in this region can be an important factor contributing to the high non-double-couple component. Anisotropy or fluids at the source region as discussed by Julian et al. (1998) and Miller et al. (1998) 
could be another possible explanation. More detailed source models obtained using higher frequency data and more advanced Earth models could help further unravel the complexity of this event's faulting process.

When conducting bootstrapping tests to assess uncertainties in the moment tensor solution of the $M_{\mathrm{w}} 5.92013$ April 30 earthquake due to local data variability, we found that the fault strike and dip varied by $15^{\circ}$, the fault rake varied by $25^{\circ}$, and the double-couple component varied by $10-15$ percent. The median values of the distributions obtained in the bootstrapping tests correspond to the parameters obtained in the local data inversions. Considering the solutions obtained with IPMA's hypocentre, the variability in the source parameters associated with the data bootstrapping test is larger than the variability due to the different 3-D mantle models. This is probably due to the similarity of the 3-D Earth models in this region and to the limited number of local stations in the inversions. In addition, our solutions for the $M_{\mathrm{w}} 5.92013$ April 30 earthquake are compatible with the aftershock distribution, which gives additional confidence in our solutions and allows us to identify the preferred fault plane of $319^{\circ}$ for fault strike, $54^{\circ}$ for fault dip, and $-73^{\circ}$ for fault rake. Moreover, the range of parameters that we obtain for this event in bootstrapping tests and varying the Earth models used is much smaller than the variability in values of strike, dip, and rake reported in seismic catalogues for this event. The approach used in our study exploring multiple combinations of data types and waveform modelling approaches is thus well suited to understand errors and the robustness of moment tensor inversions, notably for earthquakes of small-moderate magnitude and in regions with limited data coverage.

\subsection{Comparisons with seismic catalogues and aftershocks}

Fig. 9 shows that there are large differences between the solutions reported by various seismic agencies for the $M_{\mathrm{w}} 5.92013$ April 30 earthquake. The earthquake source models vary for fault strike by $60^{\circ}$, for fault dip by $35^{\circ}$ and for fault rake by $80^{\circ}$. These differences are always larger than the range of solutions that we obtained from our inversions and are a good example of the difficulties in constraining the source of distant, mid-ocean earthquakes. The reported earthquake hypocentre and centroid locations are up to $\sim 35 \mathrm{~km}$ away from each other (Fig. 13). All agencies that estimate the non-double component of this earthquake find a substantial nondouble component, in agreement with our findings. This suggests a discernible component of source complexity, which may contribute to the large variability of the reported moment tensor solutions.

The aftershock distribution can provide important information about the location, dimension and orientation of the ruptured fault. Fig. 14 shows the distribution of aftershocks of the $M_{\mathrm{w}} 5.92013$ Azores earthquake reported by IPMA (IPMA 2016). Despite not being relocated and showing considerable scattering, this set of aftershocks gives relevant information on the earthquake's dipping direction and aids in discriminating the main fault plane from the auxiliary fault plane. The majority of the aftershocks cluster in the NW-SE direction, covering an area of $\sim 20 \mathrm{~km}$ by $12 \mathrm{~km}$ with a maximum depth extent of $10 \mathrm{~km}$. The hypocentre of the main shock determined by IPMA is located at the NW end of the cluster, which is used as a centroid location in our moment tensor analysis. The aftershock distribution supports a fault plane dipping in a NE direction, with a strike of $\sim 315^{\circ}$ and a dip of $\sim 45^{\circ}$, which agrees well with our solution. Apart from this earthquake cluster, there are a few earthquakes south of the main shock aligning in a WNW-ESE direction.

\subsection{Limitations}

One limiting factor of this study is the azimuthally non-uniform distribution of local stations due to a lack of ocean-bottom seismometers around the Azores islands. The seismic modelling is limited in frequency due to the low resolution of the available Earth Structure models of the region. Moreover, a larger number of 1-D and 3-D Earth models would be desirable to further quantify the effects of Earth structure on the moment tensor solutions. The 3D Earth models used are relatively similar for the source-receiver paths at local and regional scales considered in this study, and give similar results in the earthquake modelling with local data. For seismic waves measured at teleseismic distance, the waveforms differ more significantly for the different 3-D mantle models, which is evident when comparing the misfit values in Table 3 . In addition, future work may explore centroid location determinations in the $3-D$ inversions. Some previous studies have examined source depth errors (Tilmann et al. 2010; Sumy et al. 2013; Hauksson et al. 2014; Aderhold \& Abercrombie 2015), which may deserve a future investigation.

\section{CONCLUSIONS}

Studying oceanic earthquakes remains a challenging task due to the limited coverage with local seismic stations. In moment tensor inversions of five earthquakes in the Azores archipelago, we observe a large variability of the fault parameters of $15^{\circ}-30^{\circ}$ in fault strike, $5^{\circ}-20^{\circ}$ in fault dip and $20^{\circ}-60^{\circ}$ in rake, depending on the different 1-D and 3-D Earth structure models used. The 1-D modelling emphasizes that using the velocity structure from receiver function studies can improve the seismic moment tensors solutions. The $M_{\mathrm{w}} 5.92013$ April 30 Povoação basin earthquake (SW of the São Miguel island) shows a non-double-couple component of $\sim 40-60$ per cent. A complex rupture in a curved fault recently mapped in the Povoação basin may be the reason for this large non-double-couple component, as the isotropic component of 6-13 per cent cannot be the source of the observed complexity. Performing bootstrapping tests to quantify uncertainties due to the data lead to a variability of $\sim 15^{\circ}$ in the retrieved fault strike and dip angles, $25^{\circ}$ in rake and 10 15 percent in the non-double-couple component. This is smaller than the errors due to varying the 1-D Earth models used in the inversions of this event, and much smaller than the differences between the values reported in seismic catalogues. The earthquake's location influences the moment tensor inversions strongly, especially when using local seismic data. We find that using the hypocentre determined by IPMA - the local Portuguese seismic agency - helps stabilize the inversions and leads to compatible solutions from local and teleseismic data. Moreover, when using IPMA's location, the joint inversion of local and teleseismic data helps reduce source parameter trade-offs and the variability of the solutions, compared to inversions of local data alone. This study shows that provided that an accurate location is used in the modelling, teleseismic data can provide constraints on mid-ocean earthquakes coherent with those from local data, and the joint analysis of teleseismic and local data further tightens the solutions. In the absence of local data, it may be possible to obtain constraints on the earthquake location using bathymetry information, macroseismic data and geological information. 

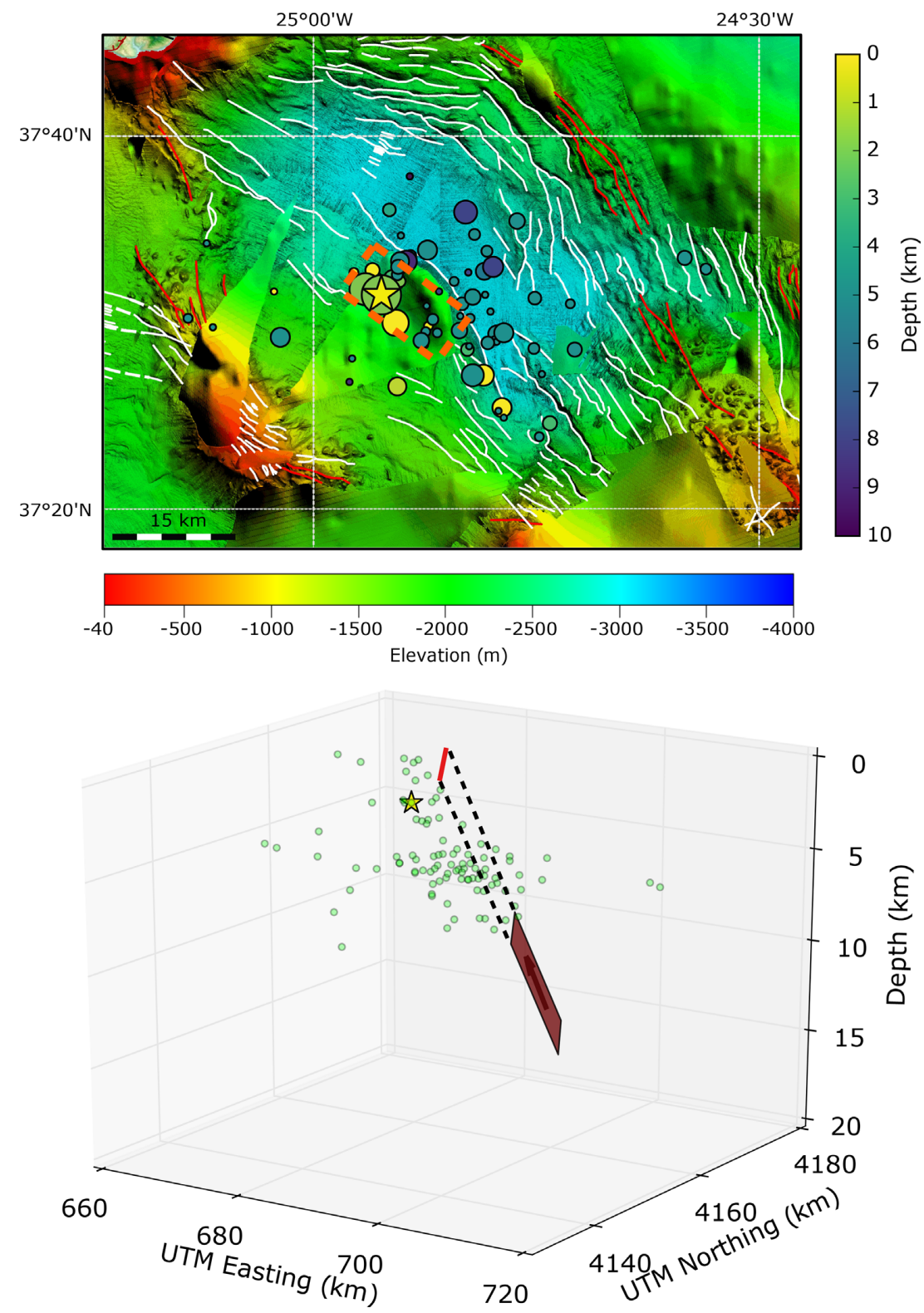

Figure 14. Top: aftershock distribution of the $M_{\mathrm{w}} 5.9$ Povoação basin earthquake on 2013 April 30, based on the IPMA catalogue with earthquakes $M_{\mathrm{w}}>2$ occurring within $14 \mathrm{~d}$ after the event (IPMA 2016). The main shock is marked by a yellow star. All other events are marked by circles, which are colour-coded according to depth. The white lines are faults, and the red lines illustrate volcanic lineaments (after Weiß et al. 2015). The dashed red rectangle is the rupture area projected to the surface. The fault length and width are estimated from scaling relations (Blaser et al. 2010). Bottom: 3-D view of the aftershock distribution. The aftershocks are marked by green circles, the main shock with a yellow star, the projected surface breakout of the fault is in red and the rupture surface is coloured in dark red for dimensions obtained using scaling relations from Blaser et al. (2010).

\section{DATA AND RESOURCES}

Software: ISOLA (Sokos \& Zahradník 2008), MATLAB, SPECFEM3D_GLOBE, version 7.0.0 (Komatitsch \& Tromp 1999, 2002a,b).

Scientific python: ObsPy (Beyreuther et al. 2010) in version 1.0.3 (The ObsPy Development Team 2017), matplotlib (Hunter 2007), numpy (van der Walt et al. 2011), pandas (McKinney 2010).

GMT (Wessel et al. 2013), Inversion code of Clarke/Wright with Powell-Downhill (Powell 1964).

Data: local data from Azores islands and mainland Portugal were provided by IPMA,

teleseismic data were retrieved from the IRIS data centre:
The facilities of IRIS Data Services, and specifically the IRIS Data Management Center, were used for access to waveform, metadata or products required in this study. The IRIS DS is funded through the National Science Foundation and specifically the GEO Directorate through the Instrumentation and Facilities Program of the National Science Foundation under Cooperative Agreement EAR-1063471. Some activities of are supported by the National Science Foundation EarthScope Program under Cooperative Agreements EAR-0733069 and EAR-1261681.

Networks used: GSN: IU (Albuquerque Seismological Laboratory/USGS 1988), IRIS IDA II (Scripps Institution Of Oceanography 1986), Caribbean CU (Albuquerque Seismological Laboratory/USGS 2006), China IC (Albuquerque Seismological 
Laboratory/USGS 1992), Geoscope G (Institut De Physique Du Globe De Paris and Ecole Et Observatoire Des Sciences De La Terre De Strasbourg 1982), Geofon GE (GEOFON Data Centre 1993) and MedNet MN (MedNet Project Partner Institutions 1990).

\section{ACKNOWLEDGEMENTS}

We gratefully acknowledge support from the AQUAREL project (PTDC/CTE-GIC/116819/2010) funded by the Fundação para a Ciência e Tecnologia (FCT), Portugal and from NERC project NE/N011791/1. We also thank support from a UCL Impact studentship and MF thanks support from a Royal Astronomical Society grant. We thank the authors of Weiß et al. (2015) for providing the bathymetric information and tectonic structure around the Povoação Basin. We thank Yehuda Ben-Zion, Gareth Funning, Phil Meredith, Piero Poli and Daniel Stich for fruitful discussions.

\section{REFERENCES}

Abercrombie, R.E. \& Ekström, G., 2001. Earthquake slip on oceanic transform faults, Nature, 410(6824), 74-77.

Abercrombie, R.E. \& Ekström, G., 2003. A reassessment of the rupture characteristics of oceanic transform earthquakes, J. geophys. Res., 108(B5).

Aderhold, K. \& Abercrombie, R.E., 2015. Seismic rupture on an oceaniccontinental plate boundary: strike-slip earthquakes along the Queen Charlotte-Fairweather Fault, Bull. seism. Soc. Am., 105(2B), 1129.

Aderhold, K. \& Abercrombie, R.E., 2016. The 2015 Mw 7.1 earthquake on the Charlie-Gibbs transform fault: repeating earthquakes and multimodal slip on a slow oceanic transform, Geophys. Res. Lett., 43(12), 6119-6128.

Albuquerque Seismological Laboratory/USGS, 1988. Global Seismograph Network (GSN - IRIS/USGS).

Albuquerque Seismological Laboratory/USGS, 1992. New China Digital Seismograph Network.

Albuquerque Seismological Laboratory/USGS, 2006. . Caribbean USGS Network.

Bassin, C., Laske, G. \& Masters, G., 2000. The current limits of resolution for surface wave tomography in North America, EOS Trans. Am. geophys. Un., 81, S12A-03.

Becker, J.J. et al., 2009. Global bathymetry and elevation data at 30 arc seconds resolution: SRTM30_PLUS, Mar. Geod., 32(4), 355-371.

Ben-Zion, Y. \& Ampuero, J.-P., 2009. Seismic radiation from regions sustaining material damage, J. geophys. Int., 178(3), 1351-1356.

Bergman, E.A. \& Solomon, S.C., 1988. Transform fault earthquakes in the North Atlantic: source mechanisms and depth of faulting, J. geophys. Res., 93(B8), 9027.

Bergman, E.A. \& Solomon, S.C., 1990. Earthquake swarms on the MidAtlantic Ridge: products of magmatism or extensional tectonics? J. geophys. Res., 95(B4), 4943.

Beyreuther, M., Barsch, R., Krischer, L., Megies, T., Behr, Y. \& Wassermann, J., 2010. ObsPy: a Python toolbox for seismology, Seismol. Res. Lett., 81(3), 530-533.

Bird, P., 2003. An updated digital model of plate boundaries, Geochem. Geophys. Geosyst., 4(3).

Blaser, L., Kruger, F., Ohrnberger, M. \& Scherbaum, F., 2010. Scaling relations of earthquake source parameter estimates with special focus on subduction environment, Bull. seism. Soc. Am., 100(6), 2914-2926.

Borges, J., Bezzeghoud, M., Buforn, E., Pro, C. \& Fitas, A., 2007. The 1980, 1997 and 1998 Azores earthquakes and some seismo-tectonic implications, Tectonophysics, 435(1-4), 37-54.

Bouchon, M., 1981. A simple method to calculate Green's functions for elastic layered media, Bull. seism. Soc. Am., 71(4), 959-971.

Buforn, E., Udías, A. \& Colombás, M., 1988. Seismicity, source mechanisms and tectonics of the Azores-Gibraltar plate boundary, Tectonophysics, 152(1-2), 89-118.
Cannat, M. et al., 1999. Mid-Atlantic Ridge-Azores hotspot interactions: along-axis migration of a hotspot-derived event of enhanced magmatism 10 to 4 Ma ago, Earth planet. Sci. Lett., 173(3), 257-269.

Chang, S.-J., Ferreira, A.M.G., Ritsema, J., van Heijst, H.J. \& Woodhouse, J.H., 2015. Joint inversion for global isotropic and radially anisotropic mantle structure including crustal thickness perturbations, J. geophys. Res., 120(6), 4278-4300.

Coutant, O., 1989. Program of numerical simulation AXITRA, Tech. Rep., LGIT, Grenoble, France.

Crotwell, H.P., Owens, T.J. \& Ritsema, J., 1999. The TauP toolkit: Flexible seismic travel-time and ray-path utilities, Seismol. Res. Lett., 70(2), 154160.

Custódio, S., Lima, V., Vales, D., Cesca, S. \& Carrilho, F., 2016. Imaging active faulting in a region of distributed deformation from the joint clustering of focal mechanisms and hypocentres: application to the Azores-western Mediterranean region, Tectonophysics, 676, 70-89.

DeMets, C., Gordon, R.G., Argus, D.F. \& Stein, S., 1994. Effect of recent revisions to the geomagnetic reversal time scale on estimates of current plate motions, Geophys. Res. Lett., 21(20), 2191-2194.

Detrick, R.S., Needham, H.D. \& Renard, V., 1995. Gravity anomalies and crustal thickness variations along the Mid-Atlantic Ridge between $33^{\circ} \mathrm{N}$ and $40^{\circ} \mathrm{N}$, J. geophys. Res., 100(B3), 3767-3787.

Dias, N., Matias, L., Lourenço, N., Madeira, J., Carrilho, F. \& Gaspar, J., 2007. Crustal seismic velocity structure near Faial and Pico Islands (AZORES), from local earthquake tomography, Tectonophysics, 445(34), 301-317.

Dreger, D., Uhrhammer, R., Pasyanos, M., Franck, J. \& Romanowicz, B., 1998. Regional and far-regional earthquake locations and source parameters using sparse broadband networks: a test on the Ridgecrest sequence, Bull. seism. Soc. Am., 88(6), 1353-1362.

Duputel, Z., Rivera, L., Fukahata, Y. \& Kanamori, H., 2012a. Uncertainty estimations for seismic source inversions, J. geophys. Int., 190(2), 12431256.

Duputel, Z., Rivera, L., Kanamori, H. \& Hayes, G., 2012b. W phase source inversion for moderate to large earthquakes (1990-2010), J. geophys. Int., 189(2), 1125-1147.

Dziewoński, A.M. \& Anderson, D.L., 1981. Preliminary reference Earth model, Phys. Earth planet. Inter, 25(4), 297-356.

Dziewoński, A.M., Chou, T.-A. \& Woodhouse, J.H., 1981. Determination of earthquake source parameters from waveform data for studies of global and regional seismicity, J. geophys. Res., 86(B4), 2825-2852.

Ekström, G., Nettles, M. \& Dziewoński, A., 2012. The global CMT project 2004-2010: centroid-moment tensors for 13,017 earthquakes, Phys. Earth planet. Inter., 200-201, 1-9.

Escartín, J., Cannat, M., Pouliquen, G., Rabain, A. \& Lin, J., 2001. Crustal thickness of v-shaped ridges south of the Azores: interaction of the MidAtlantic Ridge $\left(36^{\circ}-39^{\circ} \mathrm{N}\right)$ and the Azores hot spot, J. geophys. Res., 106(B10), 21719-21735.

Escartín, J., Smith, D.K. \& Cannat, M., 2003. Parallel bands of seismicity at the Mid-Atlantic Ridge, 12-14 n, Geophys. Res. Lett., 30(12), 1620.

Fernandes, R., Bastos, L., Miranda, J., o, N.L., Ambrosius, B., Noomen, R. \& Simons, W., 2006. Defining the plate boundaries in the Azores region, J. Volc. Geotherm. Res., 156(1), 1-9, [Volcanic geology of the Azores Islands].

Ferreira, A.M.G. \& Woodhouse, J.H., 2006. Long-period seismic source inversions using global tomographic models, J. geophys. Int., 166(3), 1178-1192.

Ferreira, A.M.G., Weston, J. \& Funning, G.J., 2011. Global compilation of interferometric synthetic aperture radar earthquake source models: 2 . effects of 3-D earth structure, J. geophys. Res., 116(8).

Frohlich, C., 1994. Earthquakes with non-double-couple mechanisms, Science, 264(5160), 804-809.

Gaspar, J.L., Queiroz, G., Ferreira, T., Medeiros, A.R., Goulart, C. \& Medeiros, J., 2015. Chapter 4: earthquakes and volcanic eruptions in the Azores region: geodynamic implications from major historical events and instrumental seismicity, Geol. Soc. Lond. Mem., 44(1), 33-49.

Gente, P., Dyment, J., Maia, M. \& Goslin, J., 2003. Interaction between the Mid-Atlantic Ridge and the Azores hot spot during the last 85 Myr: 
emplacement and rifting of the hot spot-derived plateaus, Geochem. Geophys. Geosyst., 4(10).

GEOFON Data Centre, 1993. Geofon seismic network.

Georgen, J.E. \& Sankar, R.D., 2010. Effects of ridge geometry on mantle dynamics in an oceanic triple junction region: Implications for the Azores Plateau, Earth planet. Sci. Lett., 298(1-2), 23-34.

Hauksson, E., Kanamori, H., Stock, J., Cormier, M.-H. \& Legg, M., 2014. Active Pacific North America Plate boundary tectonics as evidenced by seismicity in the oceanic lithosphere offshore Baja California, Mexico, $J$. geophys. Int., 196(3), 1619-1630.

Henry, C., Woodhouse, J. \& Das, S., 2002. Stability of earthquake moment tensor inversions: effect of the double-couple constraint, Tectonophysics, 356(1), 115-124.

Hirn, A., Haessler, H., Trong, P.H., Wittlinger, G. \& Victor, L.A.M., 1980. Aftershock sequence of the January 1st, 1980, earthquake and present-day tectonics in the Azores, Geophys. Res. Lett., 7(7), 501-504.

Hjörleifsdöttir, V. \& Ekström, G., 2010. Effects of three-dimensional earth structure on CMT earthquake parameters, Phys. Earth planet. Inter., 179(3-4), 178-190.

Hunter, J.D., 2007. Matplotlib: a 2d graphics environment, Comput. Sci. Eng., 9(3), 90-95.

Institut De Physique Du Globe De Paris, Ecole Et Observatoire Des Sciences De La Terre De Strasbourg, 1982. GEOSCOPE, French Global Network of broad band seismic stations.

IPMA, 2016. IPMA Instrumental Earthquake Database (1970-2016), Instituto Português do Mar e da Atmosfera, Lisbon, Portugal.

Julian, B.R., Miller, A.D. \& Foulger, G.R., 1998. Non-double-couple earthquakes 1. Theory, Rev. Geophys., 36(4), 525-549.

Kawakatsu, H., Takeo, A., Isse, T., Nishida, K., Shiobara, H. \& Suetsugu, D., 2014. Pacific Array, in AGU Fall Meeting Abstracts, pp. S11G-07.

Komatitsch, D. \& Tromp, J., 1999. Introduction to the spectral element method for three-dimensional seismic wave propagation, J. geophys. Int., 139(3), 806-822.

Komatitsch, D. \& Tromp, J., 2002a. Spectral-element simulations of global seismic wave propagation-I. Validation, J. geophys. Int., 149(2), 390-412.

Komatitsch, D. \& Tromp, J., 2002b. Spectral-element simulations of global seismic wave propagation-II. Three-dimensional models, oceans, rotation and self-gravitation, J. geophys. Int., 150(1), 303-318.

Konstantinou, K.I., 2015. Moment magnitude estimates for earthquakes in the greek region: a comprehensive comparison, Bull. seism. Soc. Am. ,..

Kubo, A., Fukuyama, E., Kawai, H. \& Nonomura, K., 2002. Nied seismic moment tensor catalogue for regional earthquakes around Japan: quality test and application, Tectonophysics, 356(1-3), 23-48.

Kustowski, B., Ekström, G. \& Dziewoński, A.M., 2008. Anisotropic shearwave velocity structure of the Earth's mantle: a global model, J. geophys. Res., 113(B6).

López-Comino, J.A., Stich, D., Ferreira, A.M.G. \& Morales, J., 2015. Extended fault inversion with random slipmaps: a resolution test for the 2012 Mw 7.6 Nicoya, Costa Rica earthquake, J. geophys. Int., 202(3), $1505-1521$.

Luis, J., Miranda, J., Galdeano, A. \& Patriat, P., 1998. Constraints on the structure of the Azores spreading center from gravity data, Mar. Geophys. Res., 20(3), 157-170.

Marques, F., Catalão, J., DeMets, C., Costa, A. \& Hildenbrand, A., 2013. GPS and tectonic evidence for a diffuse plate boundary at the Azores Triple Junction, Earth planet. Sci. Lett., 381, 177-187.

Matias, L. et al., 2007. The 9th of July 1998 Faial island (Azores, North Atlantic) seismic sequence, J. Seismol., 11(3), 275-298.

McKinney, W., 2010. Data structures for statistical computing in Python, in Proceedings of the 9th Python in Science Conference, pp. 51-56.

MedNet Project Partner Institutions, 1990. Mediterranean Very Broadband Seismographic Network (MedNet).

Mendes, V., Madeira, J., Brum da Silveira, A., Trota, A., Elosegui, P. \& Pagarete, J., 2013. Present-day deformation in São Jorge island, Azores, from episodic GPS measurements (2001-2011), Adv. Space Res., 51(8), $1581-1592$.

Miller, A.D., Foulger, G.R. \& Julian, B.R., 1998. Non-double-couple earthquakes 2. Observations, Rev. Geophys., 36(4), 551-568.
Miranda, J., Luis, J., o, N.L. \& Goslin, J., 2014. Distributed deformation close to the Azores Triple Point, Mar. Geol., 355, 27-35.

Mustać, M. \& Tkalĉić, H., 2016. Point source moment tensor inversion through a Bayesian hierarchical model, J. geophys. Int., 204(1), 311-323.

Pan, J., Antolik, M. \& Dziewoński, A.M., 2002. Locations of midoceanic earthquakes constrained by seafloor bathymetry, J. geophys. Res., 107(B11), EPM 8-1-EPM 8-13.

Powell, M.J.D., 1964. An efficient method for finding the minimum of a function of several variables without calculating derivatives, Comput. J., 7(2), 155-162.

Pro, C., Buforn, E. \& Udías, A., 2007. Rupture length and velocity for earthquakes in the Mid-Atlantic Ridge from directivity effect in body and surface waves, Tectonophysics, 433(1-4), 65-79.

Ritsema, J., Deuss, A., van Heijst, H.J. \& Woodhouse, J.H., 2010. S40RTS: a degree-40 shear-velocity model for the mantle from new Rayleigh wave dispersion, teleseismic traveltime and normal-mode splitting function measurements, J. geophys. Int., 184(3), 1223-1236.

Ross, Z.E., Ben-Zion, Y. \& Zhu, L., 2015. Isotropic source terms of san jacinto fault zone earthquakes based on waveform inversions with a generalized CAP method, J. geophys. Int., 200(2), 1267-1278.

Rössler, D., Krüger, F., Pšenčík, I. \& Rümpker, G., 2007. Retrieval of source parameters of an event of the 2000 West Bohemia earthquake swarm assuming an anisotropic crust, Stud. Geophys. Geod., 51(2), 231-254.

Schilling, J.-G., 1975. Azores mantle blob: rare-earth evidence, Earth planet. Sci. Lett., 25(2), 103-115.

Schilling, J.G., Zajac, M., Evans, R., Johnston, T., White, W., Devine, J.D. \& Kingsley, R., 1983. Petrologic and geochemical variations along the Mid-Atlantic Ridge from $29^{\circ} \mathrm{N}$ to $73^{\circ} \mathrm{N}$, Am. J. Sci., 283(6), 510-586.

Schlindwein, V., Demuth, A., Korger, E., Läderach, C. \& Schmid, F., 2015. Seismicity of the Arctic mid-ocean Ridge system, Polar Sci., 9(1), 146157.

Scognamiglio, L., Magnoni, F., Tinti, E. \& Casarotti, E., 2016. Uncertainty estimations for moment tensor inversions: the issue of the 2012 May 20 Emilia earthquake, J. geophys. Int., 206(2), 792-806.

Scripps Institution Of Oceanography, 1986. IRIS/IDA Seismic Network.

Searle, R.C., 1976. Lithospheric structure of the Azores plateau from Rayleigh-wave dispersion, J. geophys. Int., 44(3), 537-546.

Š́lený, J., 2004. Regional moment tensor uncertainty due to mismodeling of the crust, Tectonophysics, 383(3-4), 133-147.

Silva, R., Ferreira, T., Medeiros, A., Carmo, R., Luis, R., Wallenstein, N., Bean, C. \& Sousa, R., 2015. Chapter 17: seismic activity on São Miguel Island volcano-tectonic structures (Azores archipelago), Geol. Soc. Lond. Mem., 44(1), 227-238.

Silveira, D., Gaspar, J.L., Ferreira, T. \& Queiroz, G., 2003. Reassessment of the historical seismic activity with major impact on S. Miguel Island (Azores), Nat. Hazards Earth Syst. Sci., 3(6), 615-623.

Silveira, G., Vinnik, L., Stutzmann, E., Farra, V., Kiselev, S. \& Morais, I., 2010. Stratification of the earth beneath the Azores from $P$ and $S$ receiver functions, Earth planet. Sci. Lett., 299(1-2), 91-103.

Simons, F.J., Nolet, G., Georgief, P., Babcock, J.M., Regier, L.A. \& Davis, R.E., 2009. On the potential of recording earthquakes for global seismic tomography by low-cost autonomous instruments in the oceans, $J$. geophys. Res., 114(B5).

Smith, D.K., Escartín, J., Cannat, M., Tolstoy, M., Fox, C.G., Bohnenstiehl, D.R. \& Bazin, S., 2003. Spatial and temporal distribution of seismicity along the northern Mid-Atlantic Ridge $\left(15^{\circ}-35^{\circ} \mathrm{N}\right)$, J. geophys. Res., 108(B3).

Smith, G.P. \& Ekström, G., 1997. Interpretation of earthquake epicenter and $\mathrm{cmt}$ centroid locations, in terms of rupture length and direction, Phys. Earth planet. Inter., 102(1), 123-132.

Sokos, E. \& Zahradník, J., 2008. ISOLA a Fortran code and a Matlab GUI to perform multiple-point source inversion of seismic data, Comput. Geosci., 34(8), 967-977.

Sokos, E. \& Zahradník, J., 2013. Evaluating centroid-moment-tensor uncertainty in the new version of ISOLA software, Seismol. Res. Lett., 84(4), 656-665.

Stähler, S.C. \& Sigloch, K., 2014. Fully probabilistic seismic source inversion - Part 1: efficient parameterisation, Solid Earth, 5(2), 1055-1069. 
Stähler, S.C. \& Sigloch, K., 2016. Fully probabilistic seismic source inversion - Part 2: modelling errors and station covariances, Solid Earth, 7(6), $1521-1536$.

Sumy, D.F., Gaherty, J.B., Kim, W., Diehl, T. \& Collins, J.A., 2013. The mechanisms of earthquakes and faulting in the Southern Gulf of California, Bull. seism. Soc. Am., 103(1), 487.

Tape, W. \& Tape, C., 2015. A uniform parametrization of moment tensors, J. geophys. Int., 202(3), 2074-2081.

The ObsPy Development Team, 2017. Obspy 1.0.3.

Tilmann, F.J., Craig, T.J., Grevemeyer, I., Suwargadi, B., Kopp, H. \& Flueh, E., 2010. The updip seismic/aseismic transition of the Sumatra megathrust illuminated by aftershocks of the 2004 Aceh-Andaman and 2005 Nias events, J. geophys. Int., 181(3), 1261-1274.

USGS, 2017. USGS Earthquakes Eventpage. https://earthquake.usgs.gov/ earthquakes/eventpage/us2013pqaf

Valentine, A.P. \& Trampert, J., 2012. Assessing the uncertainties on seismic source parameters: towards realistic error estimates for centroid-momenttensor determinations, Phys. Earth planet. Inter., 210, 36-49.

van der Walt, S., Colbert, S.C. \& Varoquaux, G., 2011. The NumPy array: a structure for efficient numerical computation, Comput. Sci. Eng., 13(2), 22-30.

Vavryčuk, V., 2002. Non-double-couple earthquakes of 1997 January in West Bohemia, Czech Republic: evidence of tensile faulting, J. geophys. Int., 149(2), 364-373.

Vogt, P.R., 1979. Global magmatic episodes: new evidence and implications for the steady-state mid-oceanic ridge, Geology, 7(2), 93.

Wéber, Z., 2006. Probabilistic local waveform inversion for moment tensor and hypocentral location, J. geophys. Int., 165(2), 607-621.

Weiß, B., Hübscher, C. \& Lüdmann, T., 2015. The tectonic evolution of the Southeastern Terceira Rift/São Miguel region (Azores), Tectonophysics, 654, 75-95

Wessel, P., Smith, W.H.F., Scharroo, R., Luis, J. \& Wobbe, F., 2013. Generic mapping tools: improved version released, EOS, Trans. Am. Geophys. Un., 94(45), 409-410.

Weston, J., Ferreira, A.M.G. \& Funning, G.J., 2011. Global compilation of interferometric synthetic aperture radar earthquake source models: 1 . Comparisons with seismic catalogs, J. geophys. Res., 116(8).

Weston, J., Ferreira, A.M.G. \& Funning, G.J., 2012. Systematic comparisons of earthquake source models determined using InSAR and seismic data, Tectonophysics, 532-535(0), 61-81.

Weston, J., Ferreira, A.M.G. \& Funning, G.J., 2014. Joint earthquake source inversions using seismo-geodesy and 3-D earth models, J. geophys. Int., 198(2), 671-696.

\section{SUPPORTING INFORMATION}

Supplementary data are available at $G J I$ online.

Figure S1. Top: $P$-wave speed $V_{p}$ shown up to a depth of $50 \mathrm{~km}$ for the following 1-D earth models: IPMA (Portuguese local seismic agency), PREM, CRUST2.0 extended with PREM at $80 \mathrm{~km}$ depth and the different receiver function models from Silveira et al. (2010). Bottom: density $\rho$ profiles for the different models.

Figure S2. Top: quality factor $Q_{\kappa}$ shown up to a depth of $50 \mathrm{~km}$ for the following 1-D earth models: IPMA (Portuguese local seismic agency), PREM, CRUST2.0 extended with PREM at $80 \mathrm{~km}$ depth and the different receiver function models from Silveira $e t a l$. (2010). Bottom: quality factor $Q_{\mu}$ for the different models. The quality factors for the CRUST2.0 model and the Earth models based on the receiver functions are taken from PREM.

Figure S3. Comparison of the 1-D local data inversion results for the five earthquakes studied and the nine earth models considered for: the centroid depth (top), the centroid time-shift (time-shift of centroid time to the epicentral time) (bottom left) and the seismic moment (bottom right). The source parameter solutions are colourcoded according to their variance reduction and marked by different symbols according to the earth model used in the inversion.

Figure S4. Comparison of the moment tensor solutions obtained from inversions of different single data sets for the Povoação basin earthquake with $M_{\mathrm{w}} 5.9$ on 2013 April 30. The results of the local 1$\mathrm{D}$ modelling inversions are marked by different symbols according to the 1-D earth model used. The 3-D modelling results are marked by different symbols according to the mantle model used in the inversion. The source parameters are shown for four different data types: using local data, teleseismic $P$ waves, teleseimic $S$ waves and surface waves. The source parameters are shown for fault strike (top left), fault dip (top right), fault rake (bottom left) and double-couple component (bottom right). The two different colours denote the two different locations used: blue for IPMA and red for GCMT.

Figure S5. Comparison of the seismic moment values reported in seismic catalogues for the $M_{\mathrm{w}} 5.9$ Povoação basin earthquake on 2013 April 30 with those obtained in this study using different data and modelling approaches. The results of the local 1-D modelling ('1-D Local') are marked by different symbols representing the various $1-\mathrm{D}$ earth models used in the inversions. ' $1-\mathrm{D}$ Local BS' labels the results from the bootstrapping test for the 1-D modelling, performed with the best fitting receiver function model P-S RF COSEAa. '3-D Local BS' is the corresponding labelling for the bootstrapping test for the 3-D modelling using the mantle model S362ANI combined with the crustal model CRUST2.0. In the subsequent two columns, 3-D modelling results are reported for inversions using local data alone and jointly with teleseismic $P, S$ and surface waves. The different symbols correspond to the three mantle models used in the inversion. Finally, circles illustrate the moment tensor solutions reported by various seismic agencies (see the main text for an explanation of the agencies used). The two different colours denote the two different locations used in the inversions: blue for IPMA and red for GCMT.

Figure S6. Parameter trade-off plots and histograms for the local data set inversions using the 3-D mantle model S362ANI and the IPMA location, shown for the 40 best-fitting inversion results colour-coded by the misfit. The best-fitting solution is marked by a white star. The inversion bounds for each source parameter are illustrated by red lines. The compensated linear vector dipole component reported follows the convention of Tape \& Tape (2015).

Figure S7. Parameter trade-off plots and histograms for the joint data set inversions using the 3-D mantle model S362ANI and the IPMA location, shown for the 40 best-fitting inversion results colour-coded by the misfit. The best-fitting solution is marked by a white star. The inversion bounds for each source parameter are illustrated by red lines. The compensated linear vector dipole component reported follows the convention of Tape \& Tape (2015).

Figure S8. Histograms showing the source parameter distributions obtained in the bootstrapping inversion tests for: fault strike (top left), fault dip (top right), double-couple component (middle left), fault rake (middle right), volumetric component (bottom left) and seismic moment (bottom right). The distributions obtained from 1-D inversions are shown in blue and those obtained from 3-D inversions are shown in orange. The median value for the respective source parameter $(\tilde{x})$ is given in the legend. The median is marked with a dotted line in black for the 1-D results and in red for the 3-D results. The bootstrapping results follow Gaussian distributions for the different source parameters. The median value of the distribution is in accordance to the source parameters obtained in the inversion using all the available local data. 
Table S1. Stations in the Azores archipelago used in the source inversions. Station name, location, seismometer manufacturer, corner period of the sensorand date of installation for each station are shown. Please note the change of the sensor for the station BART in 2016.

Table S2. Moment tensor solutions from the bootstrapping tests with the 1-D modelling approach for the $M_{\mathrm{w}} 5.9$ Povoação basin earthquake on 2013 April 30, using the IPMA centroid location and the 1-D model P-S RF COSEAa. The seismic station and component which are not used in each of the inversions are given at the beginning of each line of the table. The unit of the seismic moment is in $\mathrm{Nm}$.

Please note: Oxford University Press is not responsible for the content or functionality of any supporting materials supplied by the authors. Any queries (other than missing material) should be directed to the corresponding author for the article. 